\title{
Represión, justicia y derecho en la Venezuela de hoy (2013-2019) (Repression, justice and law in today's Venezuela (2013-2019))
}

OÑATI SOCIO-LEGAL SERIES, VOLUME 10, ISSUE 4 (2020), 789-833: INVESTIGATIONS INVESTIGACIONES - IKERLANAK

DOI LINK: HTTPS://DOI.ORG/10.35295/OSLS.IISL/0000-0000-0000-1132

RECEIVED 14 SEPTEMBER 2019, ACCEPTED 07 JANUARY 2020

\author{
VICTORIA CAPRILES* (D) \\ ANDREA SANTACRUZ* ID \\ ROGELIO PÉREZ-PERDOMO* (D)
}

\section{Resumen}

Este trabajo se refiere al uso de la represión y del sistema de justicia en Venezuela durante la presidencia de Nicolás Maduro (2013-2019). En la primera parte se analiza el fenómeno de la represión, cuantificando y explicando los actos represivos y el análisis del papel del aparato de justicia en la misma. En la segunda parte hay un estudio de trece casos que ilustran la manera como procede dicha represión. Después, se analiza cómo estas acciones pueden calificarse de violaciones de los derechos humanos y aun como crímenes de lesa humanidad. Finalmente, se teoriza sobre el significado del derecho y de la profesión jurídica en un régimen político que ha violado las normas constitucionales y ha conducido al país una emergencia humanitaria compleja.

\section{Palabras clave}

Venezuela; represión; justicia; derechos humanos; crímenes de lesa humanidad

\footnotetext{
Este artículo forma parte de una serie de investigaciones llevadas a cabo por el Centro de Derechos Humanos de la Universidad Metropolitana y fue auspiciado por el Decanato de Investigación y Desarrollo Académico de la misma Universidad. Agradecemos a la estudiante de Derecho Mariangelina Socorro por la ayuda brindada como asistente de investigación.

* Victoria Capriles es abogada, magíster en Sociología Jurídica del Instituto Internacional de Sociología Jurídica (Oñati) y candidata a doctora en ciencia política de la Universidad Simón Bolívar (Caracas). Actualmente es profesora del Departamento de Estudios Internacionales y Directora Adjunta del Centro de Derechos Humanos, Universidad Metropolitana (UNIMET, Caracas, 1073). Dirección de email: vcapriles@unimet.edu.ve

* Andrea Santacruz es abogada y especialista en ciencias penales y criminológicas de la Universidad Central de Venezuela (UCV). Es profesora, jefe del Departamento de Estudios Jurídicos y Directora Ejecutiva del Centro de Derechos Humanos, UNIMET. Dirección de email: asantacruz@unimet.edu.ve

* Rogelio Pérez-Perdomo es abogado y Doctor en Ciencias, mención Derecho, de la UCV. Ll.M. (Harvard). Es profesor del Departamento de Estudios Jurídicos, exdecano de la Facultad de Estudios Políticos y Jurídicos y miembro del Consejo Consultivo del Centro de Derechos Humanos, UNIMET. Es Individuo de número de la Academia Nacional de la Historia de Venezuela. Dirección de email: rperez@unimet.edu.ve
} 


\section{Abstract}

This article refers to the use of repression and the justice system in Venezuela during Nicolás Maduro's presidency (2013-2019). In the first part, the phenomenon of repression is analyzed, quantifying and explaining repressive acts and examining the role of the judiciary in it. In the second part, there is a study of thirteen cases that illustrate the manner in which such repression is implemented. Then, we consider how these actions can be described as human rights violations and even as crimes against humanity. Finally, the meaning of law and the legal profession in a political regime that has violated all constitutional norms and has led the country into a complex humanitarian emergency is analyzed.

\section{Key words}

Venezuela; repression; justice; human rights; crimes against humanity 


\section{Table of contents}

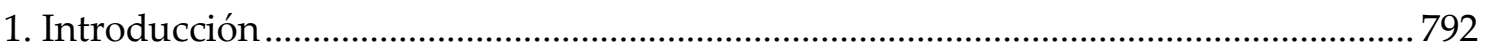

2. Poder, represión y justicia: hechos y cifras ...................................................................... 794

3. La Revolución como venganza personal: Trece casos de violaciones a los derechos

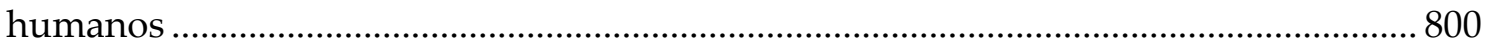

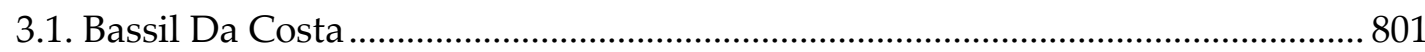

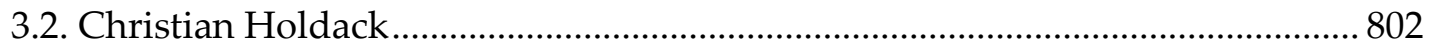

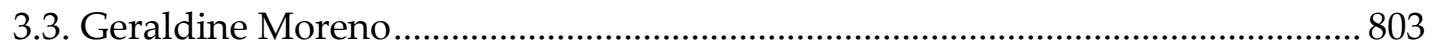

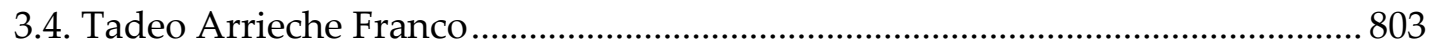

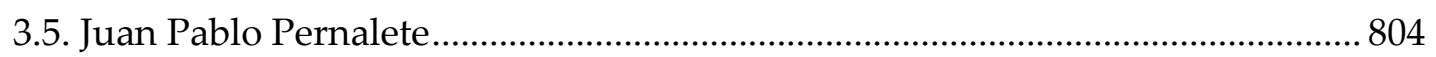

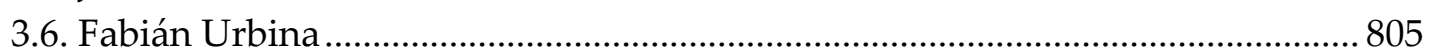

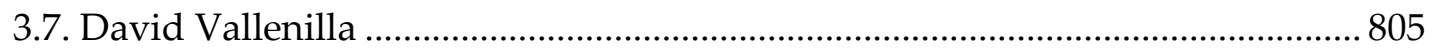

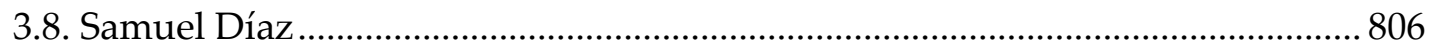

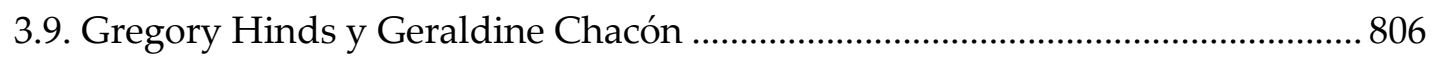

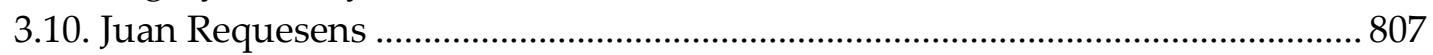

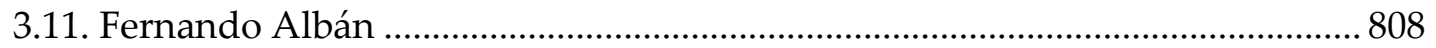

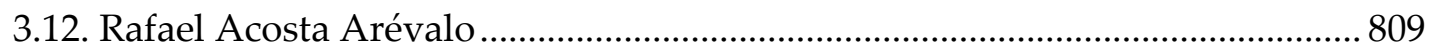

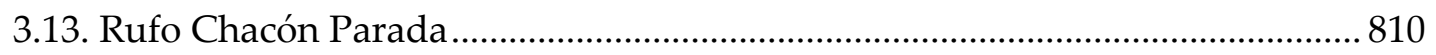

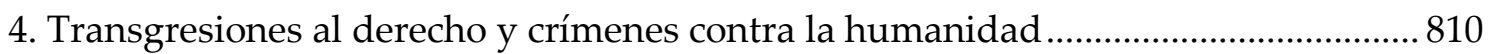

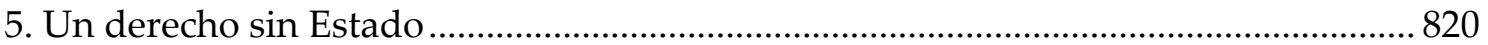

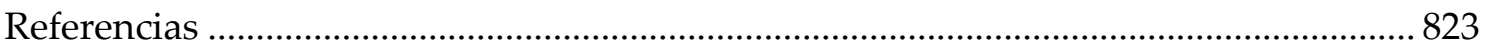

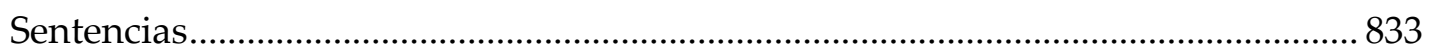




\section{Introducción}

Este trabajo se refiere al uso de la represión y del sistema de justicia en Venezuela en el período 2013-2019, que puede considerarse el tiempo presente cuando esto se escribe. El período corresponde a la presidencia de Nicolás Maduro que se ha caracterizado por tasas muy elevadas de delincuencia violenta, ${ }^{1}$ graves escándalos de corrupción, ${ }^{2}$ escasez y desabastecimiento de alimentos, medicinas e insumos y repuestos. ${ }^{3}$ La producción ha bajado sustancialmente, incluyendo la producción de petróleo, el principal producto de exportación del país. La inflación se ha acelerado hasta convertirse en hiperinflación, generalmente considerada la más alta del mundo. La pobreza y el hambre se han incrementado aceleradamente hasta el punto de ver en cualquier calle personas buscando en la basura, y también se conocen muertes por desnutrición (Fréitez Landaeta 2018, Kurmanaev 2019). Los servicios públicos tales como agua, electricidad, protección sanitaria y otros se han deteriorado sustancialmente. Enfermedades que habían desaparecido como el paludismo y la tuberculosis, han reaparecido con fuerza. La población ha reaccionado a estas calamidades con variedad de protestas pacíficas y con una migración forzada para la cual la región no está preparada. Según cifras del Alto Comisionado de las Naciones Unidas para los Refugiados (ACNUR), casi el 15 por ciento de la población ha dejado el país. 4 Todas estas afirmaciones están sustentadas con datos de organismos internacionales y de distintas ONG que operan en el país, sin embargo, no se utilizan datos oficiales porque el gobierno dejó de publicar cifras hace varios años. El Estado venezolano ha sido descrito como "una gran caja negra" debido a su opacidad (Capriles y Pérez-Perdomo 2019).

Hugo Chávez fue el líder de una enorme sacudida del sistema político y económico venezolano que llamó "revolución bolivariana" (también denominada "socialismo del siglo XXI") y que hoy se conoce popularmente como la "revolución chavista". Luego de una grave crisis política que había desprestigiado al sistema bipartidista de los años 90, Chávez se convirtió en una figura enormemente popular y fue electo presidente de la República en 1998. Una de sus primeras decisiones políticas fue la convocatoria de una asamblea constituyente, que le permitió rehacer la constitución a su medida. La implementación de políticas populistas le permitió ganar elecciones presidenciales en 2000, 2006 y 2012, y sus partidarios ocuparon la mayoría de los escaños de la Asamblea

\footnotetext{
${ }^{1}$ Datos en Briceño-León et al. 2012. El Observatorio Venezolano de Violencia en su Informe Anual del año 2019 concluyó que la tasa de muertes violentas se encuentra actualmente en 60,3 por cada 100.000 habitantes, una de las más altas de América Latina.

2 Se destaca el caso de Alejandro Andrade, quién comenzase como guardaespaldas de Hugo Chávez y fue escalando posiciones hasta convertirse en Tesorero Nacional. En 2018, fue condenado por un Tribunal estadounidense a diez años de prisión por haber aceptado mil millones de dólares en sobornos (Casey 2018). ${ }^{3}$ Por ejemplo, la ONG Acción Ciudadana Contra el Sida (ACCSI) denunció en diciembre de 2018 que la escasez de antirretrovirales alcanzaba un $95 \%$ a nivel nacional.

${ }^{4}$ Para diciembre de 2019 la cifra de refugiados y migrantes venezolanos supera los 4,7 millones (Alto Comisionado de las Naciones Unidas para los Refugiados -ACNUR- 2019). Suponemos que esta cifra no cuenta a los extranjeros residentes en Venezuela y a los hijos inmigrantes con doble nacionalidad que han regresado a su país de origen o dejado a Venezuela. De acuerdo con las proyecciones realizadas en base al Censo Nacional de 2011, la población venezolana debería estar alrededor de 32.200.000 personas (Instituto Nacional de Estadística -INE-, 2019). Contando la emigración una cifra probable conservadora de venezolanos en el país sería de 27 millones.
} 
Nacional, así, se sentaron las bases para que Chávez controlara todos los poderes del Estado (Pérez-Perdomo y Santacruz 2017).

Sus políticas económicas fueron heterodoxas. Las nacionalizaciones, expropiaciones y ocupaciones de inmuebles, fundos y empresas le otorgaron un enorme poder sobre la economía, mientras los altos precios del petróleo durante su mandato le permitieron sustituir la caída de la producción nacional con importaciones. Este mismo fenómeno de bonanza petrolera también le permitió ofrecer servicios médicos, viviendas, alimentos, artículos domésticos y otras comodidades a bajos precios o gratuitamente, lo que, naturalmente, lo hizo enormemente popular en las clases de menor poder adquisitivo. Sus políticas "antiimperialistas" y distribucionistas, así como el apoyo a Cuba y a movimientos de izquierda lo convirtieron igualmente en un líder mundial antihegemónico (Santos 2013, 2017).

En 2002 Chávez enfrentó las primeras manifestaciones masivas de la sociedad civil que se oponía a su gobierno. A pesar de que en ese mismo año se configuró un intento de derrocamiento, evento que produjo un centenar de heridos y cerca de una veintena de muertos, Chávez retomó el control rápidamente. Hubo manifestaciones pacíficas ante el cierre de medios de comunicación y otros abusos, pero el número de detenidos en esta oleada no fue alto si se compara con los índices el gobierno de Nicolás Maduro. Sin embargo, a nivel institucional y legal se gestaban cambios significativos en atención a esta realidad, pues fue en este período que el Código Orgánico Procesal Penal, que data de 1998, sufrió varias modificaciones sucesivas para permitir detenciones preventivas indefinidas y suprimir la participación ciudadana en el proceso penal (Alguindigue y Pérez-Perdomo 2013).

Chávez, afectado por un cáncer del que no se dieron detalles al público, ganó las elecciones presidenciales de octubre de 2012 luego de haber utilizado grandes recursos del Estado para su campaña. En diciembre decidió viajar a Cuba para recibir tratamiento médico, designando a Nicolás Maduro como su posible sucesor en una declaración televisada. El 5 de marzo de 2013 se anunció oficialmente su fallecimiento y en abril se realizaron nuevas elecciones presidenciales. Maduro, quien perpetuó la práctica de utilización de recursos del Estado, apeló a la figura y el legado de Chávez para atraer votantes; ganó por el 1,5 por ciento de los votos, en un severo contexto de desigualdad de recursos y sospechas de fraude (López Maya 2016).

Las condiciones de gobernabilidad para Nicolás Maduro han sido considerablemente diferentes a las de Chávez. Por una parte, carece de la conexión con la población de la que gozaba su antecesor, siendo una figura notablemente menos popular; aunado a un contexto económico de adversidades, como la severa caída de los precios del petróleo, deudas importantes que llegaron a su vencimiento, condenas en laudos arbitrales por el carácter abusivo de nacionalizaciones y expropiaciones a empresas extranjeras protegidas con contratos de inversión, ineficiencias y corrupción en las empresas estatales, incluida la petrolera PDVSA. La respuesta del gobierno de Maduro ante este marco de inestabilidad económica ha sido una política estatal conducente al control absoluto que, lejos de atender las dificultades, ha derivado en la actual situación de escasez, hiperinflación, y devaluación acelerada de la moneda, profundizando un contexto de precariedad por el cual las protestas de la población civil se multiplicaron. 
Ante estas continuas manifestaciones civiles, el gobierno ha respondido con una política sistemática y generalizada de ataque y terror en contra de la población civil disidente, desde encarcelaciones masivas, hasta agresiones, torturas y asesinatos.

En la primera parte de este trabajo se analiza la represión cuantificando y explicando los actos represivos y el análisis del papel del aparato de justicia en esa represión. En la segunda parte se describe una selección de casos que ilustran la manera como procede la represión. La tercera parte es el análisis de cómo las acciones del régimen pueden calificarse de violaciones de los derechos humanos y aun como crímenes contra la humanidad. La parte conclusiva analiza el significado del derecho y de la profesión jurídica en un régimen político que ha violado las normas constitucionales y ha conducido a la situación catastrófica que vive el país.

Los autores de este trabajo están vinculados al Centro de Derechos Humanos de la Universidad Metropolitana y, en consecuencia, han sido participantes u observadores cercanos del desarrollo de los eventos. Hay algunos elementos de autoetnografía que serán individualizados oportunamente, pero como investigadores académicos se han esforzado en tomar distancia frente a los eventos. Las aproximaciones metodológicas escogidas -cuantificación y análisis de casos-, tienen como propósito el permanecer lo más apegado posibles a los hechos estudiados y luego realizar el análisis jurídico. La parte conclusiva es integradora e interpretativa. El lector comprenderá que las situaciones y actos narrados son tragedias humanas respecto a las cuales los autores no pueden permanecer indiferentes.

\section{Poder, represión y justicia: hechos y cifras}

La realidad venezolana es compleja. La legitimidad del gobierno de Nicolás Maduro, especialmente desde el año 2013, ha sido fuertemente cuestionada, y su popularidad en declive lo ha hecho perder liderazgo, incluso dentro de las facciones alineadas con su gobierno. Por otra parte, la revolución chavista que se ha gestado en los últimos años, con el objeto de controlar de forma absoluta el aparato estatal, generó un quiebre institucional, que, aunado a otros factores, hizo posible que se gestara una devastadora emergencia humanitaria compleja. ${ }^{5}$ Los venezolanos de distintas líneas de pensamiento político participaron en las elecciones parlamentarias del año 2015, apuntando a una posible recomposición de fuerzas en el parlamento que permitiría limitar el poder del ejecutivo. Aun cuando los candidatos opositores ganaron una mayoría calificada, su poder de control fue prontamente neutralizado por el Tribunal Supremo de Justicia, que, de facto, eliminó el poder legislativo (Pérez Perdomo y Santacruz 2016) y evitó el referéndum revocatorio convocado por la oposición a finales de 2016. Ante la falta de mecanismos institucionales, las manifestaciones ciudadanas incrementaron exponencialmente en las calles del país. La respuesta del gobierno, dentro de su política de control, fue hacer uso sistemático y generalizado de la fuerza excesiva como método de represión, y por medio de la intimidación, minimizar las voces disidentes mediante la agresión perpetrada por las fuerzas armadas, cuerpos policiales y grupos

\footnotetext{
${ }^{5}$ Se entiende como "emergencia humanitaria compleja" a aquellas crisis humanitarias que tienen un origen político -debilitamiento del Estado, conflictos civiles, hundimiento de la economía-, a diferencia de otras que surgen debido a catástrofes naturales. Esta definición fue acuñada por la Naciones Unidas a partir de la década de los ochenta (Pérez de Armiño y Areizaga 2000).
} 
paramilitares armados, quienes han sido una pieza fundamental del sistema de represión.

Es de destacar que la escasez de alimentos y medicinas es seguramente el problema percibido por la sociedad como el que genera mayor alejamiento del gobierno y sus políticas. La respuesta ha sido, en lugar de cambiar y reparar las políticas económicas que han generado la escasez y desinversión; profundizar la revolución y luchar contra "especuladores". Ha habido represión contra industriales y comerciantes. Por otra parte, las políticas económicas sistémicas más recientes incluyen mecanismos como la creación del carnet de la patria y las cajas Clap. El carnet de la patria es una especie de tarjeta de identificación y bancaria, otorgada por el Estado, que requiere el usuario comprometa, no sólo sus datos personales, sino su lealtad con el gobierno. La tarjeta es utilizada para recibir transferencias directas de dinero desde el gobierno y/o para poder comprar a precios más económicos (mediante subsidios gubernamentales) alimentos, medicinas y otros artículos básicos. Así las cosas, la tarjeta cumple funciones de tarjeta de racionamiento, de provisión de fondos y de débito, pero aún más, de compromiso político. Por su parte, las cajas Clap (por Comités Locales de Abastecimiento y Producción) son cajas con productos de la dieta básica que se venden principalmente en zonas populares, a bajo precio. El gobierno sostiene que la escasez es producto de la guerra económica que el imperialismo desarrolla en contra de Venezuela y el carnet de la patria y las cajas Clap son la muestra del compromiso del gobierno con el bienestar de los venezolanos. En realidad, funciona como un mecanismo de chantaje: el costo de no comprometerse con el chavismo es la compra de alimentos y medicinas a mayor precio, en el fortuito caso de tener acceso a ellos (Acceso a la Justicia 2019). La estrategia, sin embargo, ha perdido impacto, pues la distribución de las cajas Clap se ha hecho irregular y los productos no siempre tienen la calidad acostumbrada por los consumidores venezolanos, generando descontento con el gobierno, en lugar de la buscada lealtad.

Estas políticas no son nuevas dentro del chavismo. Las misiones fueron mecanismos clientelares para generar beneficios a la población y lealtades para el partido. Las misiones eran proveedoras de servicios de distinto tipo (salud, educación, vivienda, etc.), pero la crisis económica las ha llevado a perder eficacia (Gómez 2015). Respecto a la provisión de alimentos, la política era la importación de alimentos a gran escala y la distribución supermercados y ferias controlados por el gobierno, pero donde cualquiera podía comprar. El carnet de la patria no es sino una manera de tecnificar el concepto de las misiones y mejorar la posibilidad de control político de los ciudadanos. Las cajas Clap son una forma de evitar las enormes filas frente a supermercados o lugares donde se establecían las ferias y proveer de alimentos a quienes declaren su lealtad el régimen. Esto no siempre ha sido efectivo y todavía es posible ver largas filas en algunos espacios.

Adicionalmente, un problema que preocupa al régimen y afecta profundamente a la sociedad venezolana es el incremento de la delincuencia violenta y la consiguiente inseguridad personal: robos, secuestros y homicidios se normalizaron en todo el territorio nacional, especialmente en Caracas. Este incremento comenzó a notarse en la década de 1990, era, ya para ese entonces, una de las fuentes de malestar que llevó a Hugo Chávez al poder. En esa década la tasa fue de 20 muertes violentas por cada 100 mil habitantes, el promedio para América Latina. Bajo Chávez, esta tasa incrementó rápidamente. Entre 2000 y 2005 la tasa promedio fue de 37 muertes violentas por cada 
100 mil habitantes, y entre 2006 y 2011, fue de 54 muertes violentas por cada 100 mil habitantes. ${ }^{6}$ En el período que analizamos, las cifras han tenido una variación interesante. En 2016 se alcanzó la cifra de 90 muertes por cada 100 mil habitantes. Para 2019, la cifra bajó a 60,3 muertes violentas por cada 100 mil habitantes, cuestión que debe considerarse en el marco de un fenómeno de migración que ha mermado a la población venezolana, ya que se estima que quedan aproximadamente 27 millones de habitantes en el país -casi 15\% de la población ha emigrado. El cuadro 1 muestra esa variación en cifras absolutas, que están entre las más altas de América Latina.

\section{CUADRO 1}

\begin{tabular}{|l|c|c|c|c|c|c|c|}
\hline & $\mathbf{2 0 1 3}$ & $\mathbf{2 0 1 4}$ & $\mathbf{2 0 1 5}$ & $\mathbf{2 0 1 6}$ & $\mathbf{2 0 1 7}$ & $\mathbf{2 0 1 8}$ & $\mathbf{2 0 1 9}$ \\
\hline Homicidios & ------ & ------ & ----- & 18.330 & 16.046 & 10.422 & 6.588 \\
\hline Resistencia & ------ & ----- & ----- & 5.281 & 5.535 & 7.523 & 5.286 \\
\hline Averiguación & ------ & ------ & ----- & 4.968 & 5.035 & 5.102 & 4.632 \\
\hline TOTAL & 24.713 & 24.980 & 27.875 & 28.479 & 26.616 & 23.047 & 16.506 \\
\hline
\end{tabular}

Cuadro 1. Muertes violentas en Venezuela (2013-2019).

(Fuente: Observatorio Venezolano de Violencia. Informes anuales. Nota: Homicidios son los tramitados como tales por la policía. Resistencia a la autoridad: personas muertas por resistir a la policía. Averiguación: la policía todavía no ha determinado la causa de la muerte.)

Es de notar, sin embargo, que a partir de 2015 las estadísticas de la policía comenzaron a discriminar las cifras de muertes violentas, y solo se reportan como "homicidios" los casos en los cuales el Ministerio Público decide actuar; cuando no existe esta respuesta, los casos se consideran "en averiguación". De la misma forma, "resistencia a la autoridad" es utilizado para referirse a la muerte de personas resultado de enfrentamientos con cuerpos policiales, pero estos casos, comunes en demasía, no se tramitan como homicidios (comunicación personal de Roberto Briceño-León, director del Observatorio Venezolano de la Violencia). Esta práctica no era desconocida en el pasado, pero se notó un incremento desde 1999, al inicio del gobierno de Chávez (Ávila 2017, p. 71). Entre enero del año 2000 y noviembre del 2007 la Fiscalía General de la República recibió 6.405 denuncias de casos de "ajusticiamiento" o "enfrentamientos" que sumaban 7.243 fallecidos a manos de la policía, lo que hace un total aproximado de 900 personas por año (Ortega 2012, p. 296). En definitiva, bajo la gestión del gobierno de Maduro, la policía ha sido más letal, ${ }^{7}$ mientras el gobierno exhibe como un logro la baja sustancial de las cifras de homicidio (Ávila 2017).

\footnotetext{
${ }^{6}$ Cifras publicadas por el Observatorio Venezolano de la Violencia. Ver Briceño-León et al. 2012.

${ }^{7}$ Conforme señaló la Alta Comisionada para los Derechos Humanos de Naciones Unidas en el informe presentado ante el Consejo de Derechos Humanos de Naciones Unidas el 5 de julio de 2019: "Las autoridades clasifican las muertes violentas resultantes de las operaciones de seguridad como 'resistencia a la autoridad'. El número de estas muertes es inusualmente alto. En 2018, el Gobierno registró 5.287 muertes violentas en esa categoría, en tanto que la ONG Observatorio Venezolano de la Violencia (OVV) notificó por lo menos 7.523 muertes violentas de esa categoría. Entre el 1 de enero y el 19 de mayo de 2019, el Gobierno notificó 1.569 muertes violentas por 'resistencia a la autoridad'. El OVV informó de al menos 2.124 de esas muertes entre enero y mayo de 2019. La información analizada por el ACNUDH indica que muchas de esas muertes violentas pueden constituir ejecuciones extrajudiciales" (Oficina del Alto Comisionado de las Naciones Unidas para los Derechos Humanos 2019).
} 
El grado de violencia en las actividades delictivas en Venezuela no fue un producto espontáneo. La prédica revolucionaria justificó la violencia y la exaltó, a la vez que minó los mecanismos institucionales de control (Briceño-León et al. 2012). Desde el gobierno se crearon grupos parapoliciales y paramilitares, construyendo la idea de armar al pueblo para que defendiera la revolución desde sus bases. Los grupos armados fueron llamados "colectivos", a pesar de que la versión oficial establece que son "cuadrillas de paz" (PROVEA 2019b). Estos grupos armados usaron sus armas para asaltar, extorsionar y cometer otros delitos, y durante su desarrollo como grupos delincuenciales, entraron en conflicto con bandas armadas preexistentes que no necesariamente se justificaban políticamente. Las distintas bandas se han disputado el control de determinados territorios y, a partir del año 2017, el gobierno creó las llamadas "zonas de paz": partes del país controladas por colectivos, con acceso restringido y en las cuales los cuerpos policiales no pueden ingresar.

El poder político de estas bandas (o "colectivos") es considerable, y están protegidas incluso de resistencia que pueda generarse en las mismas esferas gubernamentales. Ejemplo de esto es el caso del General Miguel Rodríguez Torres -considerado un hombre clave del régimen y estrecho colaborador de Chávez-, quien trató de controlar una de las bandas en octubre de 2014, lo que lo llevó a perder su cargo como ministro del Interior (Hernández 2014). Actualmente está preso, acusado de conspirar contra el gobierno de Maduro. Igualmente, Mariela Casado, juez-presidente del Circuito Judicial del Estado Bolívar, condenó a Wilmer Brizuela (mejor conocido como "Wilmito"), un jefe criminal conectado con el gobierno. Brizuela ordenó su muerte, y por error el sicario asesinó a la hermana de la juez en 2010. Casado no tuvo más alternativa que abandonar su cargo e irse del país. Brizuela, con varias condenas por homicidio, se encontraba en febrero de 2017 vacacionando en la Isla de Margarita con permiso especial del Ministerio de Asuntos Penitenciarios cuando fue herido de bala en la playa. Al mes siguiente sería asesinado por una banda rival dentro del Centro Penitenciario de Aragua (Moreno 2017).

Así las cosas, es evidente que las formas de control y de represión son cuestionables desde el punto de vista del derecho y de un Estado constitucional de derecho. Los "colectivos" o bandas armadas apoyadas por el gobierno son parte de la estrategia de control político y social, pero son también fuente de delitos violentos, además de ser una figura absolutamente contrarias a la idea del Estado de derecho (Von Bergen 2014).

En 2015 el gobierno implementó planes de seguridad, con el presunto objeto de "controlar la criminalidad" que afectaba especialmente a las zonas de bajos recursos de las ciudades, no obstante, organizaciones de derechos humanos -como COFAVICsostienen que en realidad lo que se ha implementado han sido sistemas de control social y castigo ejemplarizante, con altos niveles de violencia y que no apuntaban a los criminales de las zonas (García Marco 2016). El proyecto más significativo en este sentido fue la denominada OLP (Operación de la Liberación del Pueblo), luego OHLP (Operación Humanista de Liberación del Pueblo), una fuerza policial especial de la FAES (Fuerza de Acciones Especiales) que opera conjuntamente con la Guardia Nacional (cuerpo policial militarizado) y la policía de investigación (CICPC) en las zonas populares en la búsqueda de presuntos criminales (Ávila 2017).

Conforme a la narrativa oficial, estos "criminales" oponen resistencia a la captura y, en el enfrentamiento, resultan muertos. Un aspecto especialmente grave de estos operativos 
son los procedimientos previos de información y focalización de blancos, ya que son bandas civiles, aliadas del gobierno, quienes actúan como informantes y señalan las personas que deben morir. Esto explica, por una parte, el enorme incremento de los fallecidos por resistencia a la autoridad desde julio de 2015, fecha de inicio de las OLPs, y por otra, el decreciente índice de muertes calificadas de homicidios y el decrecimiento en la cifra total de muertes violentas (Ávila 2017, 2019).

Amnistía Internacional (2018) ha denunciado que durante estos operativos

[p]riorizaron la aplicación de elementos de represión con operativos reactivos policiales para combatir el delito, en los cuales se ha reportado la comisión de allanamientos ilegales, ejecuciones extrajudiciales y torturas [que] terminan por criminalizar socialmente la pobreza, en vez de aplicar mecanismos preventivos de control de la delincuencia, el Estado ha actuado usando la fuerza de forma intencionalmente letal, en contra de la población más vulnerable y excluida socialmente. (Amnistía Internacional 2018, p. 5).

Al entender la gravedad de este panorama, es necesario recordar que cuando estas políticas se han traducidos en instrumentos regulatorios, tales instrumentos serían inconstitucionales o ilegales, pero, dado el control gubernamental de los tribunales y demás instituciones de la justicia, nunca serían declarados como tal. El ciudadano que se plantee usar los tribunales para reclamar cualquiera de estos abusos perpetrados desde el poder se arriesga perder su tiempo y esfuerzo (Canova et al. 2014) y, probablemente, se expone a consecuencias más graves.

En este contexto de violencia y poder institucional, nos planteamos realizar un estudio de eventos, específicamente, la represión de las grandes manifestaciones populares de 2014 y 2017.

La primera gran ola de protestas populares masivas -o evento- ocurrió en febrero de 2014. Maduro había sido electo presidente en elecciones cuestionadas en abril de 2013 y la situación económica y social se había deteriorado rápidamente. Había escasez de alimentos, inflación y un continuo crecimiento de la delincuencia. Las bandas armadas del gobierno se veían como uno de los factores del incremento de la violencia. Los partidos de la oposición habían optado por fortalecerse para las próximas batallas electorales, pero dos dirigentes opositores, Leopoldo López y María Corina Machado, propusieron una estrategia de movilización popular que podría conducir a la salida del régimen ("La Salida"). Las peticiones de los manifestantes eran más modestas: libertad para los presos políticos, desarme de las bandas del gobierno ("colectivos") y fin de la inseguridad personal.

Los dirigentes señalados y otros sectores sociales convocaron a una manifestación el 12 de febrero 2014, con motivo de la celebración del Día de la Juventud. La manifestación fue pacífica y muy grande. Al final de su discurso de cierre Leopoldo López pidió al público que regresaran pacíficamente a sus casas. Sin embargo, luego de terminada la actividad, la violencia estalló tras el asesinato por miembros de colectivos armados y pro-gobierno de uno de sus miembros y de un estudiante, Bassil Da Costa, a manos del SEBIN (policía política). Hubo muertos, heridos y propiedades destruidas. El gobierno desató una severa represión apoyándose tanto en la Guardia Nacional y las bandas armadas. Grupos opositores construyeron barricadas y cerraron las calles (forma de protesta conocida en Venezuela como "guarimbas"). Las manifestaciones se 
prolongaron luego por más de un mes con decenas de muertos y centenares de heridos. El Presidente Maduro llamó explícitamente a los colectivos a colaborar en controlar lo que consideró una rebelión para destruir la revolución (Pérez-Perdomo 2014).

La crisis generada llamó la atención internacional. La Unión de Repúblicas de América del Sur (Unasur) envió sus cancilleres a Caracas y se conformó un grupo con tres cancilleres y el Nuncio Apostólico para facilitar los llamados “diálogos de paz". El gobierno mantuvo la represión, pero usando más el sistema de justicia. En mayo de 2014 había 2.463 personas sometidas a juicios penales, la mayor parte estudiantes apresados en manifestaciones o en sit-ins (Pérez-Perdomo 2014).

Esta represión pareciera haber surtido efecto de forma temporal, pues el año 2015 presentó una disminución significativa en el nivel de protestas políticas en comparación al 2014. Se reportaron 5.851 manifestaciones en total, de las cuales la mayoría tenía un carácter social ${ }^{8}$ y sólo un seis por ciento estaban relacionadas a derechos civiles y políticos (Observatorio Venezolano de Conflictividad Social -OVCS- 2015, p. 4). Ese mismo año la oposición obtuvo su segunda victoria electoral en diecisiete años, con las elecciones parlamentarias de diciembre, en la cual lograron una mayoría calificada de los curules. Sin embargo, la consecuencia fue que, a partir de enero de 2016, el Tribunal Supremo de Justicia comenzó un asedio contra el parlamento, al dictar sentencias que fueron que de manera progresiva y sistemática privaron a la Asamblea Nacional de sus funciones parlamentarias y legislativas (Brewer-Carías 2017a). En medio de las crecientes tensiones políticas, la oposición intentó la realización de un referéndum revocatorio en contra del presidente, proceso que fue paralizado por el Consejo Nacional Electoral el 20 de octubre de 2016 (Redacción BBC Mundo 2016).

Finalmente, el 28 y 29 de marzo de 2017 la Sala Constitucional dictó las sentencias número 155 y 156. Brewer-Carías las calificó de punto de inflexión que consolidaron un golpe de Estado y una dictadura judicial (Brewer-Carías 2017b). Estas sentencias despojaron a la mayoría de los diputados de su inmunidad parlamentaria, y la Sentencia n. ${ }^{\circ} 156$ sostiene que:

[m]ientras persista la situación de desacato y de invalidez de las actuaciones de la Asamblea Nacional, esta Sala Constitucional garantizará que las competencias parlamentarias sean ejercidas directamente por esta Sala o por el órgano que ella disponga, para velar por el Estado de Derecho. (Sentencia N.. 156, SC/TSJ, 29 de marzo de 2017)

La pretensión de suprimir las facultades constitucionales de la Asamblea Nacional, y el hecho de que los Poderes Judicial y Ejecutivo se atribuyeran sus competencias fueron consideradas por la Fiscal General de la República Luisa Ortega Díaz una ruptura de la constitucionalidad venezolana (Redacción BBC Mundo 2017). La Organización de los Estados Americanos (2017) condenó igualmente las acciones del gobierno. Lo mismo hicieron organismos internacionales de derechos humanos (Comisión Interamericana de Derechos Humanos -CIDH- 2017) y la sociedad civil (Vivanco 2017). Por su parte, la oposición convocó a una serie de manifestaciones para el 1 de abril de 2017, exigiendo la “apertura de un canal humanitario, libertad para presos políticos y un cronograma

\footnotetext{
${ }^{8}$ Derechos laborales, seguido por solicitudes de vivienda y servicios básicos, como también por la escasez de alimentos, medicinas y productos de higiene.
} 
electoral" (OVCS 2017, p. 4), lo que dio pie a una serie de manifestaciones masivas a lo largo de todo el país, aproximadamente hasta el mes de julio.

Como respuesta a las protestas, el 4 de abril de 2017 el gobierno implementó el Plan Guaicaipuro y el 18 de abril de 2017, el Plan Cívico-Militar Zamora 200, que consolidaron el uso de las fuerzas militares, fuerzas milicianas y civiles armados para mantener y controlar el orden público. Aunque no se tienen detalles del Plan Zamora, conocemos del Plan Guaicaipuro. En él, se habla de unas "fuerzas opositoras" definidas como "personas, grupos u organizaciones que mediante acciones de calle (guarimbas) quema de cauchos, basura, saqueos [obstruyen] el libre tránsito", estas fuerzas opositoras son contrarias a la "fuerzas amigas". El lenguaje es militar: los manifestantes de la oposición son vistos y tratados como fuerzas enemigas. Esto implica que deben ser neutralizados de cualquier forma, probablemente incluso la muerte.

El Plan Zamora-200 y el Plan Guaicaipuro enmarcan la institucionalización de la represión ejercida por el Estado, reflejada en las "133 personas asesinadas, 4.000 heridas, y más de 5.000 arbitrariamente detenidas" (CIDH 2017, párr. 193). La represión estatal fue de tal magnitud que el 8 de febrero de 2018 la Fiscalía de la Corte Penal Internacional (CPI) abrió un examen preliminar sobre la situación de Venezuela, cubriendo los sucesos a partir de abril de 2017. A su vez, el Secretario General de la Organización de los Estados Americanos (OEA) designó a un panel de expertos independientes, el cual en mayo de 2018 emitió un informe en el cual concluyó que hay "fundamento suficiente (...) para considerar que los actos a los que se ha visto sometida la población civil de Venezuela, que se remontan por lo menos al 12 de febrero de 2014, constituyen crímenes de lesa humanidad" (OEA 2017, p. 463).

El régimen ha tratado de revestir de legalidad su brutal política represiva. En 2014, la Sala Constitucional del Tribunal Supremo de Justicia (Sentencia n. ${ }^{\circ} 276$ del 24 de abril de 2014) estableció que para manifestar pacíficamente en el país se requiere pedir permisos y no solo notificar a las autoridades locales, como lo establece la Ley Orgánica de Partidos, Reuniones Públicas y Manifestaciones. En esta decisión, el Tribunal autorizó que las manifestaciones que no cumplan con este requisito sean reprimidas y las personas que participen en ellas, detenidas. En 2015, el Poder Ejecutivo publicó la Resolución 008610, Normas sobre la Actuación de la Fuerza Armada Nacional Bolivariana en Funciones de Control del Orden Público, la Paz Social y la Convivencia Ciudadana en Reuniones Públicas y Manifestaciones, que permite la actuación de todos los componentes de la Fuerza Armada Nacional Bolivariana y el uso de armas de fuego en el control del orden público, que se realiza conforme a planes militares. ${ }^{9}$ Ya se han mencionado el Plan Cívico Militar Zamora-200 y el Plan Guaicaipuro.

\section{La Revolución como venganza personal: Trece casos de violaciones a los derechos humanos}

Venezuela tiene una larga trayectoria en materia de derechos humanos y en la violación de los mismos. Rómulo Gallegos, un reputado escritor que en 1948 fue el primer presidente venezolano elegido democráticamente, se convirtió en 1960, en el primer

\footnotetext{
9 Sobre la militarización del control de orden público y sus efectos terribles en materia de derechos humanos se ha pronunciado la Comisión Interamericana de Derechos Humanos (2018).
} 
presidente de la Comisión Interamericana de Derechos Humanos. El país, en su momento la democracia más estable de Latinoamérica, ha ratificado nueve de los diez principales tratados internacionales sobre derechos humanos, y ha firmado, mas no ratificado la Convención Internacional para la Protección de Todas las Personas Contra las Desapariciones Forzadas.

Por el contrario, el balance histórico-social no es positivo. El Estado ha cometido crímenes que fueron clara violación de derechos humanos, ${ }^{10}$ y sólo ha cumplido parcialmente dos de las veintidós sentencias en su contra de la Corte Interamericana de Derechos Humanos (CorteIDH). En 1976, ocurrió el asesinato de Jorge Rodríguez, guerrillero y fundador de la Liga Socialista. Murió cuando se encontraba en custodia del Estado y como producto de la tortura recibida por funcionarios policiales. Sus hijos, Jorge Rodríguez hijo y Delcy Rodríguez, han ocupado puestos de gran importancia dentro de los gobiernos chavistas, especialmente bajo Maduro. Delcy Rodríguez ha declarado públicamente que la Revolución Bolivariana es su "venganza personal" (Rodríguez, en José Vicente Hoy 2018).

Durante los últimos veinte años ha ocurrido un progresivo deterioro en materia de derechos humanos en el país. El objetivo de este segmento de la investigación es visibilizar dicho deterioro a través de trece casos emblemáticos del período 2014 al 2019, presentados en orden cronológico ascendente, que luego serán analizados como parte de una política estatal de ataque sistemático y generalizado en contra de la población civil que exprese oposición al gobierno. Todos los casos seleccionados son violaciones de los derechos humanos y algunos pueden ser considerados crímenes de lesa humanidad. Los casos han sido escogidos opináticamente para mostrar la variedad de circunstancias y de gravedad de los casos. La información fue recogida a través de un proceso de documentación, que incluye revisión de fuentes documentales y entrevistas con las víctimas, sus familiares o los abogados involucrados en los casos.

\subsection{Bassil Da Costa}

Como se comentó anteriormente, Bassil Da Costa fue el primer asesinado de la ola de manifestaciones del 2014. El 12 de febrero, Bassil, estudiante universitario de 23 años acudió a la protesta convocada en Caracas. Durante la represión, y mientras corría a la altura de la esquina de Tracabordo, parroquia La Candelaria, recibió aproximadamente a las 3:13 de la tarde un disparo con arma de fuego en la cabeza que le provocó la muerte (Osorio s.f.). El momento en que es impactado quedó registrado en varias grabaciones de infociudadanos. Minutos antes, Juancho Montoya, líder de los colectivos del 23 de Enero y del Secretariado Revolucionario de Venezuela -que agrupaba a 107 colectivos de la Gran Caracas y el estado Vargas- también había recibido un disparo con arma de fuego que le segó la vida a pocos metros de distancia (Rodelo 2019).

Seis funcionarios del Servicio Bolivariano de Inteligencia Nacional (SEBIN) y dos funcionarios de la Policía Nacional Bolivariana (PNB), ocho en total, fueron aprehendidos en correlación con el caso de Bassil, uno con medida privativa de libertad

10 El caso más conocido es llamado la "masacre de El Amparo" (1988): catorce pescadores venezolanos y colombianos fueron asesinados por un comando de fuerzas militares y policiales, confundidos con, o bajo el pretexto de que eran guerrilleros. La Corte Interamericana de Derechos Humanos condenó a Venezuela al pago de reparaciones (El Amparo v Venezuela, Sentencia del 14 de septiembre 1996). 
y siete con medidas cautelares. El juicio fue diferido en distintas ocasiones, alargando el inicio del proceso hasta el 16 de junio de 2015. No es sino hasta dos años y medio de su asesinato, el primero de diciembre de 2016, que se emitió sentencia condenatoria de 29 años y 6 meses de prisión, contra el comisario del SEBIN, José Ramón Perdomo Camacho, por los delitos de homicidio intencional calificado con alevosía y motivo innoble, y uso indebido de arma orgánica. Andry Yoswua Jaspe López, oficial de la Policía Nacional Bolivariana (PNB) también fue sentenciado a 6 años de prisión por el delito de uso indebido de arma orgánica (Amnistía Internacional Venezuela -AIVEN2018a).

\subsection{Christian Holdack}

Christian Holdack es otra de las víctimas del 12 de febrero de 2014. Después de que Bassil Da Costa fuese asesinado en las inmediaciones del Ministerio Público, algunos manifestantes empezaron a lanzar piedras y objetos contundentes a las fuerzas de seguridad y colectivos que continuaban disparando. También resultaron quemadas varias patrullas del Cuerpo de Investigaciones Científicas, Penales y Criminalísticas (CICPC). Christian, fotógrafo aficionado de 32 años había acudido a la marcha y se encontraba actuando como infociudadano -de hecho, grabó a Bassil Da Costa mientras huía de los disparos de colectivos y fuerzas de seguridad estatales. Alrededor de las 3:30 de la tarde, el CICPC detiene a más de treinta personas, trasladándolas a su sede en Parque Carabobo, entre ellas a Christian. Durante su detención fueron golpeados y agredidos por funcionarios de ese cuerpo de seguridad.

Christian Holdack fue presentado en tribunales más de cuarenta y ocho horas después de su detención, y acusado de los delitos de instigación a delinquir, incendio, daños y agavillamiento. Compartió causa con Marco Coello -estudiante de bachillerato de 18 años-, Leopoldo López, quien se entregó el 18 de febrero, y otros dos estudiantes, Damián Martín y Ángel González. ${ }^{11}$

Para el 2 de abril de 2014, un médico forense del Ministerio Público declaró que Christian presentaba un "trastorno de estrés postraumático por los hechos vivenciados", que en agosto había derivado en un "trastorno mixto ansioso-depresivo", y en septiembre, la Defensoría del Pueblo solicitó al Tribunal revisar la decisión de la prisión preventiva, pues estar detenido "[repercutió] seriamente en su salud mental y podría comprometer su salud física e integridad personal" (Amnistía Internacional 2015, párr. 4).

Finalmente, Christian fue liberado bajo medidas cautelares, otorgadas por el Tribunal Supremo de Justicia, el 17 de marzo de 2015, en respuesta a un recurso de apelación de amparo, después de haber estado en huelga de hambre, y que organizaciones como Amnistía Internacional solicitaran su liberación por motivos humanitarios. El 11 de septiembre de 2015, la juez Susana Barreiros sentenció a Christian Holdack a 10 años, 6 meses, 7 días y 12 horas en prisión. ${ }^{12}$

\footnotetext{
${ }^{11}$ Marco también fue acusado de los delitos de instigación a delinquir, incendio, daños y agavillamiento. Leopoldo López fue acusado de prácticamente los mismos delitos, salvo el de agavillamiento, que en su caso era asociación para delinquir. Demian y Ángel fueron acusados por instigación pública.

${ }^{12}$ Leopoldo López fue sentenciado a 13 años, 9 meses, 7 días y 12 horas de prisión y Marco Coello había huido del país el día anterior.
} 
En octubre del año siguiente, el fiscal encargado del juicio, Franklin Nieves, solicitó asilo en Estados Unidos y declaró públicamente a la cadena de televisión CNN que Nicolás Maduro "había ordenado personalmente el arresto de Leopoldo López" (Neuman 2015, párr. 1), que Diosdado Cabello, entonces presidente de la Asamblea Nacional, "había actuado como el alguacil” (S.I. 2016, párr. 4), y que se había forjado la evidencia del caso. De igual forma, la jueza que emitió la orden de aprehensión contra Leopoldo, Ralenis Tovar, ha declarado que lo hizo bajo amenaza de violación sexual y arresto. ${ }^{13}$ La entonces fiscal general, Luisa Ortega Díaz, negó haber sido el conducto de las amenazas.

\subsection{Geraldine Moreno}

Geraldine Moreno es otra de las víctimas de la represión del año 2014. Tenía 23 años y estudiaba citotecnología en la Universidad Arturo Michelena, en Valencia (estado Carabobo). El 19 de febrero alrededor de las 8 de la noche salió a una manifestación cerca de la puerta de su casa. Diecinueve miembros del destacamento 24 de la GNB reprimieron la manifestación. Geraldine corrió, pero tropezó y cayó, recibiendo varios disparos de perdigón a quemarropa en el rostro, por lo que pierde el noventa por ciento de la masa encefálica y el ojo derecho. A pesar de recibir atención médica inmediata falleció el 22 de febrero de $2014 .{ }^{14}$

El juicio, que comenzó el 11 de marzo de 2015, después de ser diferido nueve veces, se extendió por treinta y tres meses, celebrándose cincuenta y cinco audiencias durante la fase de juicio. Franklin Martínez, Paola Barroso, Alvin Bonilla y Francisco Caridad (todos funcionarios de la GNB) fueron acusados y sólo los dos últimos fueron sentenciados. A Bonilla se le condenó a treinta años de prisión -pena máxima en el ordenamiento jurídico venezolano- por el delito de homicidio calificado con alevosía por motivos fútiles y trato cruel en grado de complicidad y Caridad fue sentenciado a 16 años y seis meses por complicidad no necesaria y uso indebido del arma orgánica, quebrantamiento de pactos y convenios internacionales, y trato cruel a la víctima (Justicia, Encuentro y Perdón 2019).

\subsection{Tadeo Arrieche Franco}

Para 2014 la escasez -entendida como ausencia parcial de bienes- de productos de primera necesidad había alcanzado un $28 \%$ a nivel nacional, según cifras del Banco Central de Venezuela (Meza 2014). Ya en enero de ese año, se había promulgado en Gaceta Oficial n. ${ }^{\circ} 40.340$ la Ley Orgánica de Precios Justos, que busca regular el precio de varios productos, así como el margen máximo de ganancia del comerciante. Dicha ley plantea, en su artículo 10, la creación de la Superintendencia Nacional para la Defensa para los Derechos Socioeconómicos (SUNDDE), encargada de fiscalizar el cumplimiento de la normativa a través de inspecciones y fiscalizaciones a establecimientos comerciales. Además, en enero de 2015, Nicolás Maduro anunció la creación de un Estado Mayor de Guerra Económica (Staff de PanAm Post 2015), conformado predominantemente por

\footnotetext{
${ }_{13}$ Declaraciones de Ralenis Tovar en la tercera ronda de audiencias públicas para analizar la posible comisión de crímenes de lesa humanidad en Venezuela, Organización de los Estados Americanos, octubre de 2017.

${ }^{14}$ Declaraciones de Rosa Orozco en la tercera ronda de audiencias públicas para analizar la posible comisión de crímenes de lesa humanidad en Venezuela, Organización de Estados Americanos, octubre de 2017.
} 
militares, con unos cuantos jefes civiles, con el objetivo de atacar la "guerra económica" que supuestamente se estaba llevando a cabo contra el país.

El 1 de enero de 2015, funcionarios del SUNDDE fiscalizaron a la red de supermercados Día a Día, imponiendo una medida preventiva de ocupación temporal, la cual abarcaba las tiendas y oficinas administrativas de la empresa. El director de la cadena de supermercados fue detenido e imputado con el delito de boicot (comunicación personal con Tadeo Arrieche, 2019).

Uno de los abogados externos de la empresa era Tadeo Arrieche. Tadeo ejercía la defensa de su cliente ante diversos organismos administrativos, y el 8 de febrero de 2015 fue detenido por funcionarios del SEBIN, sin orden de aprehensión, en el aeropuerto internacional de la ciudad de Barcelona, estado Anzoátegui, cuando se disponía a abordar un avión rumbo a la ciudad de Panamá. Dos días más tarde, fue presentado ante tribunales en la ciudad de Caracas, imputándosele los delitos de boicot y desestabilización económica (comunicación personal con Tadeo Arrieche, 2019).

Tadeo permaneció 278 días recluido en El Helicoide, y una vez liberado, estuvo aproximadamente un año y cuatro meses con medidas cautelares de presentación de manera mensual y prohibición de salida del país. En el 2017, finalmente se realizó la audiencia preliminar del caso, declarándose en marzo de ese año el sobreseimiento de la causa "ante la inexistencia de hechos que revistieran carácter penal, según la narración de hechos y pruebas expuestas por el Ministerio Público" (comunicación personal con Tadeo Arrieche, 2019).

\subsection{Juan Pablo Pernalete}

El asesinato de Juan Pablo Pernalete corresponde a la ola de protestas de 2017. Juan Pablo, de 20 años, era estudiante de contaduría pública en la Universidad Metropolitana, becado por excelencia deportiva. El 26 de abril de 2017 se encontraba en una protesta pacífica en Altamira en Caracas. La manifestación fue reprimida y un miembro de la GNB, aún no identificado, le disparó una bomba lacrimógena directamente al pecho a una distancia aproximada de 30 metros, que le causó un "shock cardiogénico debido a una contusión hemorrágica por traumatismo cerrado de tórax a nivel precordial" (según la autopsia realizada por la Fiscalía), ocasionándole la muerte en pocos minutos. La agresión en contra de Juan Pablo quedó registrada en video, gracias a un infociudadano que se encontraba documentando la represión.

La versión del gobierno es que Juan Pablo fue asesinado por sus propios compañeros utilizando una pistola de perno. ${ }^{15}$ De manera sorpresiva, el Ministerio Público sostuvo que la causa de muerte fue la bomba lacrimógena disparada a corta distancia, lo que generó tensiones entre la entonces fiscal, Luisa Ortega Díaz, y el gobierno de Nicolás Maduro. Con el fin de mantener esta versión oficial, Juan Pablo y su familia han sido estigmatizados por parte de altas autoridades estatales y de los medios de comunicación controlados por el Estado. Por ejemplo, Ernesto Villegas, entonces ministro del Poder Popular para la Comunicación e Información y presidente de Venezolana de Televisión, y Delcy Rodríguez, entonces ministra del Poder Popular para Relaciones Exteriores,

\footnotetext{
${ }^{15}$ Una pistola de perno cautivo es un aparato utilizado para sacrificar animales de granja (particularmente ganado bovino) en mataderos.
} 
declararon que Juan Pablo era un "terrorista" y "guarimbero" y tergiversaron los hechos, conforme al planteamiento del alto gobierno nacional (CDH-UNIMET 2018, Informe sobre el asesinato de Juan Pablo Pernalete Llovera, manuscrito no publicado enviado a diversos organismos internacionales).

De igual forma, los padres de Juan Pablo van dos veces por semana a interponer escritos ante la fiscalía, donde han debido esperar en oportunidades por largo tiempo para ser atendidos, se les han realizado comentarios hirientes en relación con la muerte de su hijo y se han referido a él de manera despectiva. Incluso, han sido abordados en lugares públicos, como supermercados, por personas desconocidas que han utilizado la muerte de su hijo y los hechos narrados por el gobierno nacional para causar un daño grave (comunicación personal con los Sres. Pernalete, 2019).

Es relevante observar que el hecho ocurrió el 26 de abril de 2017, una semana después que entrara en vigor el Plan Zamora y que a casi tres años del asesinato el caso se mantiene en absoluta impunidad. La investigación llevada a cabo por la Fiscalía de Derechos Fundamentales se mantiene sin resultados.

\subsection{Fabián Urbina}

Fabián Urbina, de 17 años, era un estudiante de mercadeo y publicidad, proveniente de Maracay, Estado Aragua. A pesar de que nunca había manifestado en la ciudad de Caracas, y de que había sido herido dos veces en manifestaciones en su ciudad natal, el 19 de junio de 2017, Fabián se trasladó hasta la capital, con el objetivo de participar en la protesta denominada "La Toma de Caracas", convocada por la oposición. En el momento de su asesinato, se encontraba en el distribuidor Altamira, Municipio Chacao. De acuerdo con el Informe del Panel de Expertos Independientes de la OEA (2018, p. 39) durante esa manifestación "estaban presentes efectivos de la GNB que, sin previo aviso, desenfundaron sus armas y comenzaron a disparar contra la multitud". Ese día hubo cinco heridos de bala, incluyendo un estudiante de la Universidad Metropolitana, que recibió un disparo en el hombro, y Fabián, que recibió un disparo en el pecho, falleciendo a los pocos minutos, alrededor de las 3:30 de la tarde. Su muerte fue grabada por varios infociudadanos y medios de comunicación.

El 4 de julio de 2019, dos años después de la muerte de Fabián y tras veinte diferimientos de la audiencia preliminar, el sargento segundo de la GNB, Johan Rojas, fue llevado a juicio, al considerarlo el principal autor material del asesinato (Morales 2019). Hasta los momentos no hay una sentencia condenatoria.

\subsection{David Vallenilla}

David Vallenilla, estudiante de enfermería de 22 años, se encontraba manifestando en la autopista Francisco Fajardo, en la ciudad de Caracas, el 22 de junio de 2017, cuando un militar de la aviación le disparó con una escopeta para perdigones de goma desde la parte interna de la base aérea La Carlota. El disparo impactó en el pecho y le ocasionó la muerte en pocos minutos. Según sus familiares, cuatro esferas metálicas fueron extraídas de su cuerpo, las cuales no estaban diseñadas para ser disparadas por el arma que fue utilizada. El momento del disparo quedó grabado en video (Amnistía Internacional Venezuela 2018b). 
Tres meses después de su asesinato, el 4 de septiembre de 2017, el sargento primero de la aviación Arli Cleiwi Méndez fue imputado por los delitos de homicidio calificado ejecutado con alevosía y por motivo fútil y uso indebido de arma orgánica. Se le decretó medida privativa de libertad. La audiencia preliminar fue diferida en múltiples ocasiones, hasta que fue celebrada en agosto de 2018 (Vallenilla 2018, Guillén 2018). Aún no hay sentencia y la familia ha reiterado en distintas ocasiones la necesidad de continuar las averiguaciones con respecto al resto de la cadena de mando de la aviación.

\subsection{Samuel Díaz}

Samuel Díaz era el presidente de la Federación de Centros de Estudiantes de la Universidad Metropolitana para el período 2016-2017. El 1 de junio de 2017, en el programa Con Amorín, dirigido por Jorge Amorín y transmitido por VTV, Andrés Eloy Méndez, entonces Director General de la Comisión Nacional de Telecomunicaciones (CONATEL), atacó a Samuel por convocar a una manifestación pacífica hasta la sede de VTV declarando "siempre a donde convocan hay muerte, hay violencia (...) si aquí llegara a suceder algo con los trabajadores de VTV o con los vecinos, ¿el señor Samuel Díaz va a responder esto?" (Versión Final 2017), amenazándolo además con ser detenido. El 23 de junio, Samuel presentó una denuncia ante el Ministerio Público contra Méndez, por los delitos de instigación pública y trato inhumano o degradante. El Ministerio Público no dio respuesta.

El 16 de julio de 2017 se realizó una "consulta nacional" convocada por la Asamblea Nacional. Cinco universidades autónomas se encargaron de ser garantes del proceso, declarando que más de 7 millones de venezolanos participaron en el mismo, con el 98\% rechazando la convocatoria de la Asamblea Nacional Constituyente y solicitando la realización de nuevas elecciones (Prensa Unidad Venezuela 2017). Varios expresidentes latinoamericanos participaron como observadores y se reunieron luego con miembros del movimiento estudiantil venezolano, incluyendo a Samuel Díaz y Johanna García, ambos de la UNIMET. Tres días más tarde, el 19 de julio, en Con el Mazo Dando, Diosdado Cabello acusó a Samuel y Johanna de ser "terroristas de ultraderecha" (Con El Mazo Dando 2017).

\subsection{Gregory Hinds y Geraldine Chacón}

La Fundación Embajadores Comunitarios (FEC) era una ONG sin fines de lucro, creada en 2008, que tenía como objetivo implementar "programas de empoderamiento juvenil dirigidos a adolescentes que viven en contextos de exclusión, con la finalidad de mejorar sus creencias sobre su propio valor y sus habilidades para mejorar sus vidas y su ambiente" 16 a través de modelos de Naciones Unidas.

El 17 de enero de 2018, en el programa de televisión Con El Mazo Dando, se indicó que FEC se encargaba "de adoctrinar a jóvenes del pueblo venezolano sobre lo bueno que es el capitalismo". El 31 de enero de 2018, funcionarios adscritos SEBIN, se presentaron en la sede de FEC, e ingresaron sin orden judicial de allanamiento, en búsqueda de los directivos de la Fundación. El Director General, Gregory Hinds, abogado venezolanobarbadense, se apersonó en la sede la Fundación, y los funcionarios de seguridad le

\footnotetext{
${ }^{16}$ Tal y como aparecía en su página web (http://embajadorescomunitarios.org.ve), ahora desactivada.
} 
solicitaron lo acompañaran a El Helicoide para una "entrevista". Él los acompañó sin que en ese momento se le indicara que estaba siendo detenido ni los motivos de su aprehensión. Sin embargo, en la madrugada se le notificó que estaba detenido (CDHUNIMET 2018, Informe sobre las detenciones arbitrarias de los Directivos de la Fundación Embajadores Comunitarios. Manuscrito no publicado enviado a diversos organismos internacionales).

Esa misma madrugada del primero de febrero, fue detenida en su residencia Geraldine Chacón, directora del Programa Embajadores, abogada egresada de la UNIMET y estudiante de Estudios Liberales en la misma institución, por funcionarios del SEBIN, quienes, sin orden de aprehensión, le pidieron que los acompañara a El Helicoide, porque le "harían una entrevista", y luego la regresarían a su casa. Al igual que Gregory, una vez que ingresó en el edificio y transcurridas varias horas, se le comunicó que estaba detenida (CDH-UNIMET 2018, Informe sobre las detenciones arbitrarias de los Directivos de la Fundación Embajadores Comunitarios. Manuscrito no publicado enviado a diversos organismos internacionales).

El 5 de febrero, más de noventa y seis horas desde su detención, se produjo la audiencia de presentación de Geraldine y Gregory, imputándoseles los delitos de instigación pública y agavillamiento. Transcurridos 45 días desde la audiencia y dado que el fiscal no los acusó ni presentó ningún otro acto conclusivo, el 2 de abril el tribunal ordenó su libertad inmediata e impuso medidas cautelares, pero el SEBIN se negó a recibir las boletas de excarcelación, afirmando que "ellos actuaban como un tribunal independiente" (declaración de Andrea Santacruz, abogada de Gregory Hinds). Durante todo este tiempo ni Geraldine ni Gregory salieron al sol. Además, Gregory fue recluido en una celda de castigo, de $2 \times 2$ metros, sin acceso al agua potable, por lo que tuvo que tomar agua de un retrete que se encontraba en la celda (CDH-UNIMET 2018. Informe sobre las detenciones arbitrarias de los Directivos de la Fundación Embajadores Comunitarios. Manuscrito no publicado enviado a diversos organismos internacionales).

El 1 de junio de 2018, Gregory y Geraldine fueron liberados bajo medidas cautelares, junto a otros treinta y ocho detenidos en el marco de decisiones políticas, no judiciales. Los prisioneros seleccionados fueron llevados hasta la Casa Amarilla, sede de la Comisión de la Verdad, Justicia y Paz, creada por la Asamblea Nacional Constituyente y entonces presidida por Delcy Rodríguez. A un año y medio de su detención, el proceso se encuentra todavía en fase de investigación.

\subsection{Juan Requesens}

El 4 de agosto de 2018, el entonces ministro para la Comunicación y la Información Jorge Rodríguez, informó que en el acto público de conmemoración de los 81 años de la Guardia Nacional hubo un "atentado" contra la vida de Nicolás Maduro. La oposición política mostró escepticismo al respecto y varios medios de comunicación reseñaron distintas versiones de lo ocurrido. ${ }^{17}$

El 7 de agosto, el diputado Juan Requesens, fue detenido en su casa junto a su hermana, líder estudiantil de la Universidad Central de Venezuela, Rafaela Requesens. Dos días después, alrededor de treinta funcionarios de las fuerzas de seguridad del Estado,

\footnotetext{
17 Por ejemplo, ver Smith y Armario 2018 y El País 2018.
} 
fuertemente armados, allanaron su casa sin orden judicial. Al día siguiente, el Tribunal Supremo de Justicia en Sala Plena y con ponencia del magistrado Maikel Moreno, decretó que la detención del diputado había ocurrido en flagrancia (a pesar de que ocurrió, en efecto, días después de los hechos por los que se le detuvo), remitiendo la actuación a Diosdado Cabello, presidente de la Asamblea Nacional Constituyente, para que allanara la inmunidad del parlamentario, aunque constitucionalmente esto es competencia de la Asamblea Nacional (Acceso a la Justicia 2019).

El 10 de agosto, Jorge Rodríguez hizo público un video en cual Requesens, quien se ve desorientado y confundido, confiesa su participación en los hechos. Horas después, se filtra otro video en el que el parlamentario, se encuentra semidesnudo, con la ropa interior sucia, y un hombre no identificado le solicita que se coloque de frente y espaldas a la cámara. El partido de Requesens, Primero Justicia, denunció que había sido drogado, y que no recordaba haber grabado ninguno de los dos videos (Prieto 2019).

Cuatro días más tarde (14-08-18), en la audiencia de presentación, se le imputaron los delitos de instigación pública continuada, terrorismo, financiamiento al terrorismo, asociación para delinquir, homicidio calificado por motivo fútil en grado de frustración, homicidio calificado con alevosía en grado de frustración y posesión ilícita de armas y municiones. El 1 de julio de 2019, casi un año después, la juez Carol Padilla declaró la admisión de los cargos imputados y ordenó el pase a juicio (Prieto 2019). El proceso continúa cuando esto se escribe.

\subsection{Fernando Albán}

Fernando Albán, concejal del Municipio Libertador (Caracas) y dirigente del partido Primero Justicia, fue detenido en el aeropuerto el 5 de octubre de 2018 cuando llegaba de un viaje, pues se le relacionaba con los hechos del 4 de agosto de 2018, los mismos que mantienen a Juan Requesens privado de libertad.

Durante 48 horas, ni sus abogados ni familiares tuvieron conocimiento de su paradero, hasta que fue llevado a tribunales, donde se difirió su audiencia de presentación e imputación para el lunes 8 de octubre, ya que el tribunal que se encontraba de guardia no era desde donde se había supuestamente ordenado su aprehensión. En ese momento se conoció que había estado recluido y permanecería en la sede del Sebin en Plaza Venezuela (Olmo 2018).

El lunes 8 de octubre, Tarek William Saab declaró a Venezolana de Televisión que Albán se había suicidado, lanzándose del baño del piso 10 del Sebin de Plaza Venezuela. Esta versión la sostendría nuevamente dos días después. Néstor Reverol, Ministro de Relaciones Interiores, Justicia y Paz, dio otra versión en su cuenta de Twitter: Albán habría caído desde "la sala de espera del Sebin" (Reverol 2018). Sus familiares, abogados y compañeros de partido rechazaron estas versiones, y sostienen que fue asesinado o que probablemente murió al ser torturado.

El 2 de septiembre de 2019 el Ministerio Público imputó a Keyberth Cirelli y Miguel Dos Santos, funcionarios del SEBIN, por el delito menor de quebrantamiento de las obligaciones de custodia, al haberle retirado las esposas a Albán sin permiso de sus superiores. De igual forma, la Fiscalía solicitó el pase del caso a la etapa de juicio (EFE 2019, Rodríguez 2019). 


\subsection{Rafael Acosta Arévalo}

El 20 de mayo de 2018 tuvo lugar un proceso electoral convocado por la Asamblea Nacional Constituyente sin atender a los plazos establecidos en la Constitución y en la cual la oposición se negó a participar. Como era previsible, Nicolás Maduro resultó electo pero la elección fue desconocida por la oposición política y decenas de Estados. Zeid Ra'ad Al Hussein, entonces Alto Comisionado de las Naciones Unidas para los Derechos Humanos, señaló que en el país no se cumplían "de ninguna manera las mínimas condiciones para unas elecciones libres y creíbles" (EFE 2018).

La tensión aumentó cuando Maduro se juramentó como presidente el 10 de enero de 2019, y, casi dos semanas después, el 23 de enero, el presidente de la Asamblea Nacional, Juan Guaidó, respaldándose en los artículos 233, 333 y 350 de la Constitución, se juramentó como Presidente Encargado de la República, siendo reconocido por más de 50 Estados y por la Organización de Estados Americanos.

Esto trajo consigo una nueva ola de protestas. El Observatorio Venezolano de Conflictividad Social documentó 10.477 manifestaciones en los primeros seis meses del 2019, 97\% más que en el mismo período de 2018. Estas culminaron con 61 asesinados y cientos de detenidos (Observatorio Venezolano de Conflictividad Social 2019).

El 21 de junio de 2019, el capitán de corbeta en situación de retiro, Rafael Acosta Arévalo, fue detenido por funcionarios de la Dirección General de Inteligencia Militar (DGCIM) mientras se encontraba en un centro comercial de la ciudad de Guatire, estado Miranda. Se señaló que estaba involucrado "en un golpe de Estado que tendría lugar entre el 23 y el 24 de junio" (Plazas 2019). Jorge Rodríguez hijo, ministro de Comunicación e Información, señaló que Acosta era un "terrorista confeso" y habría sido imputado de los delitos de terrorismo, sedición, y magnicidio en grado de frustración. $\mathrm{Ni}$ sus familiares ni sus abogados supieron de su paradero hasta que fue trasladado el 28 de junio a una sede judicial para la realización de la audiencia de presentación. Según su abogado, el capitán Acosta llegó al tribunal en silla de ruedas, sin poder hablar y en evidente mal estado de salud por lo que el juez ordenó su traslado al hospital militar, donde fallecería en la madrugada del 29 de junio (CDH-UNIMET 2019).

Durante once días, ni los familiares ni los abogados del capitán tuvieron acceso al cuerpo. El 10 de julio, trabajadores de la morgue les permitieron a los familiares ver el rostro de Acosta, y el mismo día, ocurrió una inhumación controlada en el Cementerio del Este en Caracas, por orden judicial y en contra de los deseos de sus familiares, quienes deseaban enterrarlo en su ciudad natal de Maracay (Melgar 2019a).

El 1 de julio fueron imputados dos miembros de la DGCIM, el sargento Estiben Zárate y el teniente Ascanio Tarascio, con el delito de homicidio preterintencional. El 24 de septiembre de 2019 el tribunal 36 de Control del Área Metropolitana de Caracas sentenció a los funcionarios estatales a seis años y ocho meses en prisión. Diversas organizaciones de la sociedad civil, incluyendo a PROVEA (2019a), se pronunciaron en desacuerdo con esta decisión por considerarla "una sentencia que estimula el uso de la tortura por parte de organismos policiales y militares. Reafirma además que en Venezuela se creó una estructura institucional para favorecer el abuso de poder, las violaciones a los derechos humanos y la impunidad" (ibid., párr. 2). 


\subsection{Rufo Chacón Parada}

El 1 de julio de 2019, Rufo Chacón Parada, de 16 años, se encontraba con su madre, Adriana Parada, y su hermano, Adrián Chacón Parada, de 14 años, protestando por la falta de gas doméstico en San Cristóbal, estado Táchira. La protesta fue fuertemente reprimida por funcionarios de la Policía de Táchira (Politáchira). Adrián Chacón y otro manifestante fueron golpeados, y a Rufo le dispararon perdigones a quemarropa directamente al rostro (Melgar 2019b).

Rufo fue trasladado al Hospital Central de San Cristóbal. Según lo declarado por el presidente de la Corporación de Salud del estado Táchira, doctor Luis Ramírez, el adolescente recibió el impacto de 52 perdigones, de los cuales cuatro se alojaron en el ojo izquierdo y ocho en el derecho, lo que le ocasionó la pérdida total de la visión (Arévalo, 2019). Al día siguiente, 2 de julio, Tarek William Saab, declaró que, tras investigaciones realizadas por el Ministerio Público, se detuvo a los funcionarios de Politáchira Javier Useche Blanco y Henry Ramírez Hernández, quienes fueron imputados con los delitos de homicidio intencional calificado en grado de frustración, trato cruel y uso indebido de arma orgánica (El Nacional 2019).

El juez dictaminó que los funcionarios deberían estar recluidos en el Centro Penitenciario de Occidente, y, mientras ocurría el traslado, se mantendrían en los calabozos de la sede del CICPC en el estado Táchira. No obstante, en enero de 2020 Useche y Ramírez fueron trasladados a los calabozos de la sede de Politáchira. Hasta los momentos no hay sentencia condenatoria (TalCual 2020).

\section{Transgresiones al derecho y crímenes contra la humanidad}

La Constitución de la República Bolivariana de Venezuela garantiza una larga serie de derechos y explícitamente señala que los tratados de derechos humanos tienen jerarquía constitucional y prevalecen en el orden interno. ${ }^{18}$ Existe igualmente una profusa legislación que garantiza los derechos y un sistema de justicia que debe velar por su cumplimiento. En cuanto al derecho a la vida, la Constitución (artículo 43) lo declara inviolable y enfatiza la obligación del Estado en proteger la vida de las personas privadas de libertad o sometidas a su autoridad en cualquier forma. El Pacto Internacional de Derechos Civiles y Políticos (artículo 6) establece que todo ser humano tiene derecho a la vida, ${ }^{19}$ y el no ser arbitrariamente privado de ésta es también un derecho fundamental, que debe ser aplicado a todo momento y en toda circunstancia, incluso en conflictos armados y demás emergencias públicas (Naciones Unidas 2017). El Estado venezolano está obligado a prevenir la privación de la vida y los funcionarios de las fuerzas de

\footnotetext{
18 “Artículo 23: Los tratados, pactos y convenciones relativos a derechos humanos, suscritos y ratificados por Venezuela, tienen jerarquía constitucional y prevalecen en el orden interno, en la medida en que contengan normas sobre su goce y ejercicio más favorables a las establecidas en esta Constitución y en las leyes de la República, y son de aplicación inmediata y directa por los tribunales y demás órganos del Poder Público".

${ }^{19}$ Este derecho también se encuentra contenido en la Declaración Universal de Derechos Humanos y la Declaración Americana de los Derechos y Deberes del Hombre, el Segundo Protocolo Facultativo del Pacto Internacional de Derechos Civiles y Políticos, la Convención contra la Tortura y otros Tratos o Penas Crueles, Inhumanos o Degradantes y la Convención Interamericana para prevenir y sancionar la tortura, entre otros, que han sido firmados o ratificados por el Estado venezolano.
} 
seguridad deben actuar con base a los principios de: legalidad, necesidad y proporcionalidad en el uso de la fuerza. ${ }^{20}$

Las prácticas policiales, judiciales y políticas que muestran los casos reseñados muestran la violación de ese derecho. Siete ${ }^{21}$ de los trece casos pueden ser considerados ejecuciones extrajudiciales. Durante las protestas de 2014, además de Bassil da Costa y Geraldine Moreno fueron asesinadas otras cuarenta y una personas. De igual forma durante 2017, ciento treinta y tres ciudadanos fueron asesinados en el contexto de las manifestaciones, incluyendo a Juan Pablo Pernalete, Fabián Urbina y David Vallenilla (CIDH 2017). En cuanto a Fernando Albán y Rafael Acosta Arévalo, ambos murieron estando bajo custodia del Estado, lo que lo hace responsable de estas muertes.

Hay que destacar que en los cinco casos de asesinatos en manifestaciones pacíficas las víctimas fueron impactadas en la cabeza y el pecho, lo que demuestra que los funcionarios querían causar un daño grave, apuntando a zonas del cuerpo especialmente vulnerables. En el caso de Juan Pablo Pernalete, David Vallenilla y Geraldine Moreno, hubo además un uso inadecuado de armas menos letales, con el objeto de aumentar su letalidad. Las bombas lacrimógenas están diseñadas para ser disparadas a larga distancia, en espacios abiertos -para que los manifestantes puedan dispersarse a zonas con aire limpio-, de forma proporcionada, sólo cuando sea necesario y nunca directo al cuerpo (Bournemouth University's Civic Media Hub y The Omega Research Foundation 2016), no obstante, a Juan Pablo le dispararon el cartucho directamente al pecho y a corta distancia, utilizando la bomba como un proyectil, dándole así un uso distinto para el que fue construido.

Si bien a David Vallenilla le dispararon con una escopeta para perdigones de goma, de su cuerpo se recuperaron esferas metálicas, lo que "evidencia que [los perdigones] fueron sustituidos irregularmente por municiones letales por parte de los mismos efectivos del Estado" (Amnistía Internacional Venezuela 2018b, párr. 2). A Geraldine Moreno le dispararon los perdigones de goma directamente al rostro y a quemarropa, lo que aumentó de forma sustancial el daño causado por los mismos. Este patrón se ha continuado repitiendo, hasta el caso de Rufo Chacón, a quien también le dispararon perdigones de goma directamente al rostro y a quemarropa, que, en esta ocasión, si bien no ocasionó la muerte, le generó lesiones gravísimas y permanentes, lo que puede considerarse tortura.

Otra característica común en estos casos (que se repiten en los demás) es el retraso procesal. ${ }^{22}$ Según la Relatoría Especial Sobre las Ejecuciones Extrajudiciales, Sumarias o Arbitrarias de la ONU, el derecho a la vida va más allá de su componente material, conteniendo también un componente procesal, es decir "la necesidad de realizar una investigación adecuada y de rendir cuentas en caso de que haya motivos para creer que

\footnotetext{
${ }^{20}$ Tal y como establece los Principios Básicos sobre el Empleo de la Fuerza y de Armas de Fuego por los Funcionarios Encargados de Hacer Cumplir la Ley adoptados en 1990 por el Octavo Congreso de las Naciones Unidas sobre Prevención del Delito y Tratamiento del Delincuente.

${ }^{21}$ Bassil Da Costa, Geraldine Moreno, Juan Pablo Pernalete, Fabián Urbina, David Vallenilla, Fernando Albán y Rafael Acosta Arévalo.

${ }^{22}$ Esto ha sido denunciado como un patrón en el cual el sistema de justicia se ha convertido en brazo de la revolución, en contra del debido proceso, establecido en diversos tratados internacionales ratificados por el Estado venezolano y la CRBV en su artículo 49.
} 
se ha privado arbitrariamente de la vida a alguien" (Naciones Unidas 2014, párr. 46). El caso de Bassil Da Costa es uno de los pocos en los que ha habido algo de justicia, aunque la sentencia condenatoria se emitió dos años después de su asesinato, y no se tomó en cuenta a la cadena de mando. Esto es algo que se repite en el caso de Geraldine Moreno, en el cual solo se condenó a un funcionario cuando había varios implicados y no se investigó la cadena de mando. Los casos de Juan Pablo, Fabián y David continúan en absoluta impunidad.

Ahora bien, seis ${ }^{23}$ de los trece casos analizados pueden considerarse detenciones arbitrarias, las cuales ocurren cuando no se sigue el procedimiento establecido por la ley nacional y que contravienen la Declaración Universal de los Derechos Humanos, y que son en sí misma una violación al derecho a la libertad personal. En la Constitución venezolana se establece (artículo 44) que "ninguna persona puede ser arrestada o detenida sino en virtud de una orden judicial, a menos que sea sorprendida in fraganti. En este caso, será llevada ante una autoridad judicial en un tiempo no mayor de cuarenta y ocho horas a partir del momento de la detención". Justamente, todas las detenciones anteriormente descritas ocurrieron sin que hubiese una orden judicial o la persona se encontrara en flagrancia, además no se les permitió comunicarse con sus familiares y abogados. Esto último es una violación del derecho a la defensa y al debido proceso.

Venezuela se encontraría así en medio de una "epidemia" de detenciones: según el informe del Panel de Expertos Independientes de la OEA (2018), desde 2013 y hasta 2018 más de doce mil personas fueron arbitrariamente detenidas en todo el país. Las detenciones arbitrarias hacen vulnerables a quienes las sufren, haciéndolos más susceptibles de sufrir más violaciones a sus derechos humanos (TRIAL International 2019).

En todos los casos de detenciones arbitrarias que hemos descrito encontramos tortura y otros tratos crueles, inhumanos y degradantes. ${ }^{24}$ Christian Holdack, quien se vio envuelto en uno de los juicios más mediáticos que ha tenido el país, al ser compañero de causa de Leopoldo López, sufrió torturas y malos tratos hasta el punto de que desarrolló un trastorno de estrés postraumático, que hizo que la Defensoría del Pueblo solicitase al tribunal liberarlo de la prisión preventiva. Cinco días antes de su liberación, otro prisionero político, Rodolfo González, se había suicidado.

\footnotetext{
${ }^{23}$ Christian Holdack, Tadeo Arrieche Franco, Gregory Hinds y Geraldine Chacón, Juan Requesens, Fernando Albán y Rafael Acosta Arévalo.

${ }^{24}$ La Convención de las Naciones Unidas contra la Tortura y Otros Tratos o Penas Crueles, Inhumanos o Degradantes ofrece las siguientes definiciones: “Artículo 1. A los efectos de la presente Convención, se entenderá por el término 'tortura' todo acto por el cual se inflija intencionadamente a una persona dolores o sufrimientos graves, ya sean físicos o mentales, con el fin de obtener de ella o de un tercero información o una confesión, de castigarla por un acto que haya cometido, o se sospeche que ha cometido, o de intimidar o coaccionar a esa persona o a otras, o por cualquier razón basada en cualquier tipo de discriminación, cuando dichos dolores o sufrimientos sean infligidos por un funcionario público $u$ otra persona en el ejercicio de funciones públicas, a instigación suya, o con su consentimiento o aquiescencia. Artículo 16. Todo Estado Parte se comprometerá a prohibir en cualquier territorio bajo su jurisdicción otros actos que constituyan tratos o penas crueles, inhumanos o degradantes y que no lleguen a ser tortura tal como se define en el artículo 1, cuando esos actos sean cometidos por un funcionario público u otra persona que actúe en el ejercicio de funciones oficiales, o por instigación o con el consentimiento o la aquiescencia de tal funcionario o persona."
} 
De igual forma, funcionarios de seguridad recurren a engaños para realizar detenciones sin orden de aprehensión, por ejemplo, en el caso de Gregory Hinds y Geraldine Chacón, miembros del SEBIN les solicitaron que fuesen a su sede en El Helicoide para una entrevista, diciéndoles que una vez terminada la misma podrían irse. No obstante, lo que ocurrió una vez que ingresaron al edificio y transcurridas varias horas fue que se les notificó de su detención. El fiscal del Ministerio Público reconoció que la detención era arbitraria, y en lugar de solicitar la nulidad absoluta del caso, correspondiente al ordenamiento jurídico venezolano, invocó la sentencia n. 526 de la Sala Constitucional del Tribunal Supremo de Justicia, que, de manera anticonstitucional, ha servido de base para que ocurran detenciones sin orden de aprehensión y sin que se esté en flagrancia, ${ }^{25}$ lo cual es contrario a la constitución, pues violenta el artículo 44 de la misma, así como diversos tratados internacionales. Debe destacarse que no es claro que los magistrados hayan pretendido el fin que se le ha dado a dicha decisión, pero ella en sí misma es inconstitucional al permitir que una persona arbitrariamente detenida, pudiera permanecer en esa condición, en lugar de ser inmediatamente liberada dada la nulidad absoluta de la aprehensión.

La detención de Tadeo Arrieche también ocurre sin orden de aprehensión, sumándole además que fue en contra de los Principios Básicos sobre la Función de los Abogados de las Naciones Unidas (Comité Jurídico Interamericano 1990). ${ }^{26}$

En el caso de Juan Requesens, el Tribunal Supremo de Justicia en Sala Plena (Sentencia n. ${ }^{\circ} 48$ del 08-08-2018) decretó que su detención había sido flagrante, a pesar de que la misma sucedió tres días después de los hechos que se le imputan, siendo esto un hecho anticonstitucional. De igual forma, el diputado Requesens estuvo 120 horas incomunicado, sin que sus familiares o abogados supieran de su paradero, lo que se constituye en una desaparición forzada ${ }^{27}$ (Acceso a la Justicia 2018). En cuanto a Fernando Albán y Rafael Acosta Arévalo, también fueron desaparecidos forzosamente después de haber sido detenidos ilegalmente, el primero por 48 horas y el segundo por siete días.

\footnotetext{
${ }^{25}$ En esta sentencia, del 9 de abril de 2001, con ponencia del Magistrado Iván Rincón Urdaneta, se decretó que “... la presunta detención practicada por los organismos policiales sin orden judicial alguna, no puede ser imputada a la Corte de Apelaciones accionada, ni tampoco al Juzgado de Control que dictó el auto de privación judicial preventiva de libertad (...) ya que la presunta violación a los derechos constitucionales derivada de los actos realizados por los organismos policiales tienen límite en la detención judicial ordenada por el Juzgado de Control, de modo tal que la presunta violación de los derechos constitucionales cesó con esa orden $(. . .)^{\prime \prime}$.

26“16. Los gobiernos garantizarán que los abogados a) puedan desempeñar todas sus funciones profesionales sin intimidaciones, obstáculos, acosos o interferencias indebidas; $b$ ) puedan viajar y comunicarse libremente con sus clientes tanto dentro de su país como en el exterior; y c) no sufran ni estén expuestos a persecuciones o sanciones administrativas, económicas o de otra índole a raíz de cualquier medida que hayan adoptado de conformidad con las obligaciones, reglas y normas éticas que se reconocen a su profesión. 18. Los abogados no serán identificados con sus clientes ni con las causas de sus clientes como consecuencia del desempeño de sus funciones."

27 Según la Convención Internacional para la Protección de Todas las Personas Contra las Desapariciones Forzadas de las Naciones Unidas (artículo 2): “Se entenderá por 'desaparición forzada' el arresto, la detención, el secuestro o cualquier otra forma de privación de libertad que sean obra de agentes del Estado o por personas o grupos de personas que actúan con la autorización, el apoyo o la aquiescencia del Estado, seguida de la negativa a reconocer dicha privación de libertad o del ocultamiento de la suerte o el paradero de la persona desaparecida, sustrayéndola a la protección de la ley".
} 
Tadeo Arrieche, Gregory Hinds y Geraldine Chacón estuvieron recluidos en El Helicoide, el sitio actual detención de Juan Requesens. Las condiciones de reclusión de El Helicoide constituyen en sí mismas un trato inhumano y degradante conforme lo declaró la Corte Interamericana de Derechos Humanos en 2012 (caso Díaz Peña v Venezuela, 2012). La situación no ha mejorado en los últimos ocho años. Durante sus cuatro meses de detención, Geraldine y Gregory fueron sometidos a tratos crueles, inhumanos y degradantes, y éste último fue torturado. De igual forma, ninguno de los dos salió al sol durante su reclusión. El video la "confesión" de Juan Requesens, así como el otro video filtrado poco después, también demuestra que continúa la tortura y los tratos crueles en El Helicoide. Fernando Albán murió en otra sede del SEBIN, la de Plaza Venezuela, mientras que, debido a su desaparición forzada, no se sabe aún donde ocurrió la tortura al capitán Acosta Arévalo.

Cuando algún funcionario policial o militar es llevado a juicio no se investiga la cadena de mando, lo cual muestra la complicidad del aparato de justicia con las políticas represivas del gobierno y con las graves violaciones de los derechos humanos. Por el contrario, son frecuentes los ascensos de funcionarios públicos que han participado en la criminalización de la disidencia política. Por ejemplo, Susana Barreiros, la juez que sentenció a Christian, fue designada Defensora Pública General el 10 de diciembre de 2015 (Gaceta Oficial 40.807). Frank Osuna, entonces teniente coronel y comandante del Destacamento 24 de la Guardia Nacional, que se encontraba en la escena cuando ocurrieron los hechos que derivaron en la muerte de Geraldine Moreno, fue ascendido rápidamente hasta el rango de General en Jefe en el año 2018 (Analítica 2019).

Generalmente los lesionados, detenidos o asesinados en el marco de protestas pacíficas, ${ }^{28}$ se encontraban ejerciendo sus derechos humanos a la reunión, libertad de expresión y manifestación, consagrados en pactos y tratados internacionales en materia de derechos humanos y en el ordenamiento jurídico venezolano. De igual forma, las amenazas y ataques en contra de Samuel Díaz, en su carácter de dirigente estudiantil, son también una amenaza a los derechos humanos anteriormente descritos. Finalmente, las arremetidas en contra de Juan Requesens y Fernando Albán demuestran que los hechos del 4 de agosto de 2018 fueron utilizados para justificar una nueva ola de represalias en contra de la disidencia política incluyendo diputados de la Asamblea Nacional, como Requesens.

Estos trece casos son una muestra de la constante violación de derechos humanos en Venezuela. Sistemáticamente el derecho a la vida, integridad física, libertad de expresión y asociación, entre otros, son transgredidos. Las detenciones arbitrarias son comunes, así como la tortura, tratos crueles, inhumanos y degradantes, el no acceso a los abogados de confianza, la confesión incriminatoria en situaciones irregulares y la interferencia del Poder Ejecutivo en el aparato judicial. Todo esto ha sido respaldado por diversos organismos internacionales, siendo el más reciente el informe de la Alta Comisionada de las Naciones Unidas para los Derechos Humanos, Michelle Bachelet, publicado tras su visita a Venezuela en junio de 2019. Su informe documenta las violaciones a los derechos humanos y concluye que el Estado venezolano debe "adoptar de inmediato medidas específicas para detener y remediar las graves vulneraciones de derechos económicos,

${ }^{28}$ Bassil Da Costa, Christian Holdack, Geraldine Moreno, Juan Pablo Pernalete, Fabián Urbina, David Vallenilla y Rufo Chacón. 
sociales, civiles, políticos y culturales que se han documentado en el país" (Oficina del Alto Comisionado de las Naciones Unidas para los Derechos Humanos 2019, párr. 1).

Como la violación de los derechos humanos es sistemática y un ataque generalizado contra la población civil disidente, es indudable que son parte de una política estatal de control y quienes cometen los delitos lo hacen bajo las órdenes y con el conocimiento o aprobación de sus superiores. Por lo tanto, cabe preguntarse si estamos frente a crímenes de lesa humanidad.

Hay voces autorizadas que ya se han pronunciado afirmándolo. Una de ella es el Informe el de la Secretaría General de la Organización de Estados Americanos y el panel de expertos internacionales independientes sobre la posible comisión de crímenes de lesa humanidad en Venezuela (OEA 2018); Human Rights Watch (Vivanco y Taraciuk 2018), y Amnistía Internacional (2019) también lo afirman. Por su parte, los informes de la Oficina del Alto Comisionado para los Derechos Humanos del año 2017 y 2018 y el informe de país de la Comisión Interamericana de Derechos Humanos publicado en 2018, hacen referencia a algunos indicios; los primeros señalan que se ha observado "una política dirigida a reprimir sistemáticamente la oposición al gobierno e infundir temor entre la población" (Oficina del Alto Comisionado para los Derechos Humanos de Naciones Unidas 2018), mientras que la Comisión Interamericana de Derechos Humanos (2017) indicó que ha verificado "patrones de hostigamiento y criminalización de quienes emiten opiniones políticas o difunden información que no encuentra aprobación estatal".

Los crímenes de lesa humanidad son considerados uno de los cuatro ${ }^{29}$ crímenes atroces definidos en el Estatuto de Roma. Los mismos "constituyen una amenaza para la paz, la seguridad y el bienestar de la humanidad" (Preámbulo del Estatuto de Roma de la Corte Penal Internacional, tercer aparte). Los crímenes de lesa humanidad son definidos en el artículo 7 del Estatuto de Roma como:

Los actos siguientes cuando se cometa como parte de un ataque generalizado o sistemático contra una población civil y con conocimiento de dicho ataque:

a) Asesinato;

b) Exterminio;

c) Esclavitud;

d) Deportación o traslado forzoso de población;

e) Encarcelación u otra privación grave de la libertad física en violación de normas fundamentales de derecho internacional;

f) Tortura;

g) Violación, esclavitud sexual, prostitución forzada, embarazo forzado, esterilización forzada o cualquier otra forma de violencia sexual de gravedad comparable;

h) Persecución de un grupo o colectividad con identidad propia fundada en motivos políticos, raciales, nacionales, étnicos, culturales, religiosos, de género definido en el párrafo $3, \mathrm{u}$ otros motivos universalmente reconocidos como inaceptables con arreglo al derecho internacional, en conexión con cualquier acto

${ }^{29}$ Genocidio, crímenes de lesa humanidad, crímenes de guerra y agresión. 
mencionado en el presente párrafo o con cualquier crimen de la competencia de la Corte;

i) Desaparición forzada de personas;

j) El crimen de apartheid;

k) Otros actos inhumanos de carácter similar que causen intencionalmente grandes sufrimientos o atenten gravemente contra la integridad física o la salud mental o física. (Estatuto de Roma de la Corte Penal Internacional, 1998)

Los actos descritos anteriormente corresponden a las letras a, e, f, h, i, k. Para que configuren crímenes de lesa humanidad se requiere que ocurran como parte de: a) un ataque b) generalizado o sistemático, c) en el marco de una política del Estado o de una organización, d) dirigido en contra de una población civil y, e) quienes lo cometan tenga conocimiento de dicho ataque. Estos son entonces los elementos del tipo penal señalados en el artículo 7 del Estatuto de Roma y el documento de la CPI denominado Elementos de los Crímenes, los cuales deben ser considerados cuidadosamente.

El ataque: Cuando se habla de ataque, se entiende este como un conjunto de conductas violentas, una línea de conducta desarrollada para maltratar a una población civil. En el caso venezolano se observa que el Estado ha actuado de tal forma que ha criminalizado el ejercicio del derecho a la manifestación pacífica. Ello ha ocurrido desde los tiempos de Chávez, quien después de las manifestaciones de 2002 estimuló la creación de zonas de seguridad, aún existentes, en las que está prohibida la realización de manifestaciones de personas opuestas al gobierno nacional y quien incumpla esto puede ser detenido. Ya en ese tiempo las protestas eran reprimidas por guardias nacionales y policías de la extinta Policía Metropolitana, cuyo rol represivo fue luego asumido por la Policía Nacional Bolivariana, quienes hacían uso excesivo de la fuerza. Pero es en el gobierno de Nicolás Maduro cuando se produce un aumento exponencial del número de manifestaciones pacíficas y consecuentemente la represión violenta cobra un número mayor de víctimas.

En 2014 se produjo una importante oleada de protestas. El Observatorio Venezolano de Conflictividad Social, registró 9.286 en todo el país, de las cuales el 52\% eran en rechazo al gobierno. Durante dicho año fueron detenidas más de 3.300 personas y asesinadas 42 en el contexto de las manifestaciones, alcanzando la represión cifras históricas. Al respecto el Observatorio Venezolano de Conflictividad Social (2014) señaló:

La violencia y represión hacia manifestantes alcanzó cifras inéditas en la historia venezolana, solo comparable con los sucesos del Caracazo de 1989. Según datos oficiales, difundidos por el Ministerio Público en el mes de junio, desde febrero hasta junio se registraron 3.306 manifestantes detenidos, 973 heridos y 42 fallecidos.

Esas cifras responden al uso excesivo de la fuerza por parte de los agentes estatales (policiales y militares) quienes actuaban en conjunto con civiles (colectivos armados), autorizados a participar en las actividades de control de orden público conforme al plan cívico militar Zamora 200, del que se supo por primera vez en ese año, pero dada la gran opacidad estatal solo se conoce su existencia y que unas de sus fases es la "fase verde". La existencia de colectivos armados es inconstitucional.

Los casos documentados muestran el uso excesivo y hasta letal de la fuerza para impedir manifestaciones pacíficas, detenciones indiscriminadas e injustificadas, torturas y malos tratos. La defensa no es escuchada en los tribunales y se mantienen medidas privativas de libertad aun cuando los procesos son evidentemente inconstitucionales y no hay 
elementos de convicción que permitan considerar que las personas son autores o participes en hechos punibles. Esto ocurre una y otra vez, cuando la manifestación es convocada por los líderes políticos de oposición y miembros de la sociedad civil abiertamente disidente, incluyendo al movimiento estudiantil.

La reiteración de lo antes indicado revela que no son hechos aislados las violaciones de derechos humanos que han ocurrido en el contexto de las manifestaciones, donde pareciera que las fuerzas estatales se enfrentaran a sus peores enemigos. De hecho, se conoce que junto al plan cívico militar Zamora 200, existe el Plan Guaicaipuro, cuya puesta en marcha se inició el 4 de abril de 2017. En dicho plan se enlista a las "fuerzas amigas" y a las "fuerzas opositoras", que evidentemente en un plan militar son entendidas como enemigas.

El uso excesivo de la fuerza por parte de agentes estatales o de civiles armados actuando con anuencia de estos se desarrolla con total impunidad gracias a: a) la Sala Constitucional del Tribunal Supremo de Justicia que, con su sentencia n. ${ }^{\circ} 276$ del 24 de abril de 2014, estableció que para manifestar pacíficamente en Venezuela debe pedirse permiso y no simplemente notificar, como establecido en la ley respectiva. Las manifestaciones que no cumplan con este requisito se consideran ilegales y pueden ser reprimidas y quienes participen en ellas, detenidas; b) el poder judicial en general y el Ministerio Público, que al conocer la arbitrariedad de las acciones de represión no actúa conforme a derecho, permitiendo la impunidad. Y por último, pero no menos importante; c) el poder ejecutivo nacional que ordena la aplicación de planes militares que en la práctica han significado la militarización del control de orden público, contrariando las normas y jurisprudencia internacionales al respecto, y ha hecho pública la Resolución 008610, del Ministerio de la Defensa, que, a principio de 2015, estableció que en el control de orden público pueden actuar todos los componentes de las fuerzas armadas y pueden utilizar armas de fuego, vulnerando con ello la letra del artículo 68 de la Constitución que de forma expresa indica que no pueden emplearse armas de fuego en el control de orden público.

La criminalización de la protesta opositora al gobierno es un hecho, que a nuestro entender pretende cumplir con la política estatal de controlar a la población civil disidente mediante la intimidación.

$\mathrm{Y}$ aunque se esperaría que disminuyeran o desaparecieran las protestas en general, se evidencia un aumento considerable de las mismas, principalmente las de motivación social. El Observatorio Venezolano de Conflictividad Social (2019) documentó 10.477 protestas durante el primer semestre de 2019, cuando para ese mismo período de tiempo en 2017 registró 4.930, y en 2018, 5.315. Pero mientras más manifestaciones ocurren, mayor es la represión violenta y letal:

El OVCS y el Programa Venezolano de Educación Acción en Derechos Humanos (Provea) lograron documentar de manera conjunta la muerte de 61 personas durante el desarrollo de las manifestaciones ciudadanas, así como el asesinato de 6 personas, días después de realizadas las protestas, que fueron detenidas en sus casas y ejecutadas extrajudicialmente por participar en protestas $\mathrm{u}$ organizarlas. Las muertes ocurrieron en 17 estados del país. (OVCS 2019)

Las acciones desarrolladas por agentes estatales siguen una línea de acción de muerte, maltrato y vulneración de derechos de las personas que participan en manifestaciones 
contrarias al gobierno o en exigencias de derechos como el acceso a los servicios básicos. Las detenciones arbitrarias no solo ocurren en el contexto de manifestaciones pacíficas, también ocurren de manera selectiva, cuando privan arbitrariamente de libertad a líderes políticos como Juan Requesens, líderes sociales como Gregory Hinds y Geraldine Moreno y a un número cada vez mayor de militares, solo cuando los mismos son considerados contrarios al gobierno, como el caso del Capitán de corbeta Rafael Acosta Arévalo. Las detenciones selectivas representaron un cambio de patrón frente a las detenciones masivas y rigieron el año 2018.

Vemos entonces un ataque general constituidos por actos de asesinatos, encarcelamientos, torturas, desapariciones forzadas, que ha desarrollado el Estado como parte de una política de control, en contra de cualquier persona que sea considerada disidente, lo que lo hace generalizado y se ha estructurado un sistema para realizar este ataque con el que se pretende control a una población civil a través del terror y la intimidación.

El carácter sistemático o generalizado del ataque: Será sistemático cuando sea organizado, cuente con un patrón de conducta. Y será generalizado cuando abarque a una gran cantidad de personas. El Tribunal Penal Internacional para la Ex Yugoslavia, sobre estas características del ataque, señaló:

La Sala de Primera Instancia del TPIY en Blaškić hizo referencia a las características de una 'política' en el contexto del requisito de sistematicidad. El carácter sistemático hace referencia a cuatro elementos que, a los efectos del presente caso, pueden expresarse del modo siguiente: 1) la existencia de un objetivo político, eso es, de destruir, perseguir o debilitar a una comunidad; 2) la comisión de un acto criminal en una muy gran escala contra un grupo de civiles, o la comisión repetida y continua de actos inhumanos vinculados entre sí; 3) la preparación y el uso de recursos públicos o privados significativos, ya sean militares o de otro tipo; 4) la participación de autoridades políticas o militares de alto nivel en la definición y la determinación del plan metódico. (Lostal Becceril et al. 2017, p. 65)

Asimismo,

un crimen puede ser generalizado o cometido en una muy gran escala por el 'efecto acumulado de una serie de actos inhumanos o por el efecto singular de un acto inhumano de una magnitud extraordinaria' (...). (Lostal Becceril et al. 2017, p. 72)

Estas características se cumplen todas en el caso de Venezuela y su objetivo político es controlar a la población civil disidente mediante la intimidación, debilitando así a esa comunidad.

El ataque que aún parece estar ocurriendo es a gran escala. En este artículo hemos tomado 13 casos como referencia de muchos otros. Sobre los asesinatos hemos hablado de 7 casos, pero solo en el contexto de protestas y en los años 2014, 2017 y 2019 se contabilizaron 266 personas asesinadas. En el caso de los encarcelamientos, hemos expuesto 4 casos, cuando se habla en el país de 15.160 arrestos hasta el 19 de agosto de 2019 y 522 presos políticos (Foro Penal 2019).

Además de ser un ataque a gran escala, se observa la comisión repetida y continuada de actos inhumanos en contra de quienes expresan sus ideas en contra del gobierno, en términos como los expuestos previamente. 
En el caso específico de las manifestaciones, la orden de reprimirlas viene directamente del Poder Ejecutivo Nacional, avalado por el Poder Judicial. Recordemos que el 18 de abril de 2017, a través de los medios de comunicación social, Nicolás Maduro anunció la puesta en marcha de la fase verde del Plan Estratégico Especial Cívico Militar (Maduro, citado en TeleSur TV 2017) Zamora, ordenando a todos los comandantes de las fuerzas armadas acatar la orden que él estaba dando en su carácter de comandante en jefe de la fuerza armada nacional, "para derrotar el golpe de Estado y la escalada de violencia" (Maduro, citado en TeleSur TV 2017), que en realidad era la nueva oleada de manifestaciones pacíficas convocadas por el liderazgo opositor tras la publicación por el Tribunal Supremo de Justicia de las sentencias 155 y 156, que de facto eliminaban el Poder Legislativo Nacional. Esto parece evidenciar "la participación de autoridades políticas o militares de alto nivel en la definición y la determinación del plan metódico".

El hecho de que la orden venga pública y directamente del presidente nos permite presumir que todos aquellos que actuaron conforme al Plan cívico militar Zamora, conocen la existencia del ataque y aun así siguieron actuando.

La política estatal: El segundo párrafo del artículo 7, en su literal a, señala que el ataque implica que la actuación se desarrolle "de conformidad con la política de un Estado o de una organización de cometer esos actos o para promover esa política". La política estatal o de organizaciones implica que los actos que ocurren no son aislados o producto del azar, por el contrario, responden a un plan o a una estructura previamente establecida. $\mathrm{Al}$ respecto distintas organizaciones de derechos humanos venezolana en el Manual sobre el Derecho a la Protección Internacional en Crisis Mayores señalaron:

... puesto que resultaría casi imposible que unos individuos de manera espontánea o por iniciativa propia lleven a cabo actos con la intención de atacar a una población civil con patrones generalizados o sistemáticos sin el estímulo o dirección de una influencia externa, con falta de poder para autorizar o hacer uso de los medios de violencia necesarios, o en ausencia de la capacidad y los recursos para realizar un ataque que requiere planeación, colaboración, movilización colectiva y coordinación, independientemente de que estén o no envueltas acciones militares. Si bien los demás elementos permiten confirmar un crimen por el carácter generalizado o sistemático de los actos que prueban su naturaleza de ataque, e inferir que detrás de este ataque existe un plan o una estructura organizada preconcebida, se requiere determinar el vínculo con una 'política' a objeto de establecer las condiciones que lo provocaron y la gravedad de las responsabilidades en su ejecución como un crimen de trascendencia internacional. (Civilis Derechos Humanos et al. 2019)

Este elemento puede ser uno de los más difíciles de demostrar cuando no existe un anuncio público sobre la política estatal, pero en el caso venezolano se observan algunos posibles indicios, como: las órdenes presidenciales públicas de represión, la existencia de planes cívicos militares en los que incluso se habla de fuerzas opositoras que pueden entenderse como enemigas, el aval del Poder Judicial a estas actuaciones. El gobierno invierte sumas ingentes en material bélico y de control de orden público como puede apreciarse por la cantidad y calidad de los equipos, pero no hay acceso público a esa información. Todo ello nos deja ver que la violencia en contra de la población civil opositora o disidente no es casual ni responde a hechos aislados, es parte de una conducta desde el Estado, que pretende controlar a esta población. 
Una población civil como objeto del ataque: Por último, es muy importante determinar que el objeto principal del ataque sea la población civil, sin distinción alguna en cuanto a las características de esta población (raza, religión, identidad de género, nacionalidad, etc.), y entendiendo que entre las víctimas puede haber militares, pero que ellos no son el foco principal del ataque.

En el caso venezolano consideramos que el objeto del ataque es la población civil disidente, es decir, todas aquellas personas que no estén de acuerdo con el gobierno no sean "leales a la revolución bolivariana" y lo manifiesten públicamente, lo cual se evidencia dado el número de casos de disidentes políticos asesinados, torturados, perseguidos o encarcelados, habiendo señalado algunas de esas cifras en este artículo.

Frente a la posibilidad de que en Venezuela hayan ocurrido o estén ocurriendo crímenes de lesa humanidad, la fiscalía de la Corte Penal Internacional inició de oficio el examen preliminar sobre la situación del país, el 8 de febrero de 2018. El 27 septiembre de ese mismo año, seis Estados partes del Estatuto de Roma (Canadá, Colombia, Chile, Paraguay, Perú y Argentina) remitieron la situación a la Fiscalía y solicitaron “que inicie una investigación por crímenes de lesa humanidad presuntamente cometidos en el territorio de Venezuela desde el 12 de febrero de 2014, a fin de determinar si se ha de acusar de la comisión de tales crímenes a una o varias personas determinadas" (Corte Penal Internacional 2018, párr. 101). Por ahora el examen preliminar se encuentra en la fase 2 de las 4 que se siguen conforme al procedimiento que sigue la fiscalía de la CPI.

Recordemos que el Estado venezolano es parte del Estatuto de Roma, por lo que está obligado a investigar, juzgar y condenar a los responsables de las posibles atrocidades ocurridas en el país, pero por principio de complementariedad, si Venezuela no quiere o no puede juzgar, la Corte Penal Internacional será competente para hacerlo.

El proceso ante la Corte Penal Internacional es fundamentalmente de naturaleza judicial y puede ser lento, como lo demuestran otros casos. Es posible que tenga un impacto indirecto en la política venezolana, pero no puede ser pensado como un instrumento de poner fin a la catastrófica situación descrita en este artículo. Como académicos del derecho lo que podemos hacer es analizar las consecuencias que para el derecho tiene la conducta extrema que ha seguido el régimen venezolano.

\section{Un derecho sin Estado}

El 10 de enero 2019, Nicolás Maduro se juramentó para su segundo período de seis años (2019-2025). Lo hizo ante el Tribunal Supremo de Justicia, en contra del ritual usual de juramentación de un presidente de la República, que debe ser ante el Poder Legislativo. ¿Significa una mayor importancia de los jueces? O ¿el reiterado quiebre del Estado constitucional de derecho? El 23 de enero Juan Guaidó, presidente del Poder Legislativo, ante el hecho de que la elección de Maduro no cumplió los requisitos constitucionales ni los usuales en una democracia, se juramentó como Presidente de República encargado. Cincuenta países, incluyendo la mayoría de los países europeos y del continente americano reconocieron a Guaidó. Existe también un Tribunal Supremo de Justicia en el exilio, constituido por magistrados designados por la Asamblea Nacional después de anular la designación de trece magistrados que fueron elegidos por los anteriores miembros de la Asamblea Nacional en una madrugada fuera del tiempo de su mandato, 
sin seguir los procedimientos constitucionales y sin que la mayoría de los designados cumplieran los requisitos para ser magistrados del Tribunal Supremo.

Así las cosas, el 5 de enero de 2020 debía ocurrir la primera sesión del año de la Asamblea Nacional, sin embargo, miembros de la Guardia Nacional impidieron el acceso a los diputados de oposición, y a Juan Guaidó, al Palacio Federal Legislativo (CDH-UNIMET 2020). No obstante, los diputados de la facción chavista ingresaron sin problemas, y también lo hizo un grupo de diputados de "oposición" que habían sido expulsados de sus partidos luego de que se descubriera que estaban involucrados en un escándalo de corrupción con las cajas Clap (Deniz 2019). Estos diputados "sesionaron", sin alcanzar el quórum mínimo requerido constitucionalmente y juramentaron a Luis Parra, ex miembro de Primero Justicia, como presidente de la AN. En horas de la tarde de ese mismo día, en la sede del periódico El Nacional, y alcanzando el quórum requerido, los diputados que no pudieron ingresar al Palacio Legislativo nuevamente juramentaron a Juan Guaidó como presidente de la Asamblea, de acuerdo con lo señalado en el artículo 221 de la Constitución en concordancia con el artículo 1 del Reglamento de Interior y de Debates de la Asamblea Nacional (CDH-UNIMET 2020, Redacción Web Panorama 2020, Olmo 2020).

En definitiva, tenemos dos presidentes de la República, dos tribunales supremos, dos Asambleas Nacionales -una declarada en desacato por uno de los tribunales, la otra considerada ilegítima al haberse juramentado sin el quórum requerido por la Constitución- y una Asamblea Nacional Constituyente, electa en comicios no democráticos y realizando acciones claramente inconstitucionales. La Asamblea Nacional de mayoría opositora y el presidente encargado Juan Guaidó se apoyan en una legitimidad constitucional y democrática, y tienen reconocimiento internacional. Nicolás Maduro también se denomina presidente, ocupa el palacio presidencial y controla el aparato del Estado. La situación podría describirse como la de dos gobiernos que se declaran ilegítimos el uno al otro.

La situación práctica es aún más complicada que eso y lo que sostenemos es que no hay un Estado en el sentido moderno de esa palabra. Lo que caracteriza al Estado es el monopolio de la fuerza pública. El Estado venezolano, cuando creó fuerzas parapoliciales y paramilitares que no controla perdió el monopolio del poder. Fue esto lo que incrementó rápidamente la violencia y los asesinatos organizados bajo el nombre de "operaciones de liberación del pueblo" no le han devuelto ese monopolio. Al no poder garantizar la seguridad de los ciudadanos y al haber provocado una emigración masiva tanto por la inseguridad reinante como por no poder garantizar el funcionamiento de ningún sistema estatal, entre otros el sistema económico y generar hambruna, aguda escasez de medicamentos y de toda clase de bienes, ha dejado de cumplir las funciones del Estado. Un "Estado fallido" realmente no es un Estado.

El país no tiene la capacidad de producir derecho en forma de legislación. Las leyes aprobadas por la Asamblea Nacional han sido anuladas por el Tribunal Supremo. Este actúa en realidad como apéndice del gobierno de facto. Dos magistrados que eran prominentes miembros de la nomenklatura chavista cayeron en desgracia y son fugitivos de la justicia que han pedido protección en países extranjeros. Un tercer magistrado se adelantó a pedir esa protección y pidió refugio en los Estados Unidos. El Tribunal Supremo de Justicia fue puesto al servicio de la revolución: el gobierno no 
pierde ningún juicio, sino que, como hemos visto, trata de revestir sus decisiones de algún fundamento jurídico (Canova et al. 2014). Desde 2006 en adelante las revistas jurídicas venezolanas publican artículos mayoritariamente críticos de las decisiones del Tribunal Supremo y de la legislación del gobierno. El estudio no encontró artículos que mostraran compartir los razonamientos de los organismos del régimen (Pérez-Perdomo 2015).

En general, los abogados evitan el litigio pues toda la judicatura está al servicio de los intereses de la "revolución", pero esto no suprime las exacciones a quienes se atreven a litigar. En materia penal y si los casos tienen algún matiz político o está involucrado alguien asociado con el gobierno, el resultado es previsible pues cualquier decisión que irrite a una personalidad importante en el régimen implica destitución o consecuencias peores para el juez, como lo mostró el caso Afiuni (Pérez-Perdomo y Santacruz 2017).

Dado que la legislación no se puede tomar en serio y a los efectos prácticos no se puede contar con que los tribunales decidan conforme al derecho, la pregunta es ¿qué significa el derecho? Por esto hemos preguntado a los abogados que llevan casos de violación de derechos humanos o en general contrarios a los intereses del gobierno liderado por Nicolás Maduro en cualquier otra materia, qué sentido tiene su trabajo y para qué se molestan en ir a los tribunales, si los resultados son completamente previsibles y no van a ser decididos conforme a derecho. La respuesta es que desean dejar testimonio escrito de las injusticias como tal, lo que es una función meramente expresiva del derecho. Otros señalaron que tienen interés en agotar la jurisdicción nacional porque es imprescindible hacerlo para recurrir a tribunales internacionales. Los abogados nos han indicado que informan a sus clientes que esta vía puede ser demorada, pero que los clientes generalmente desean que el abogado actúe aun con esas bajas perspectivas respecto a la justicia. ${ }^{30}$

Claramente esta situación muestra que el derecho está disociado del Estado y de la posibilidad de coerción. Muchos abogados han decidido emigrar y se han radicado en el extranjero donde la mayoría ejerce como abogados o en alguna función relacionada con el derecho (Capriles y Pérez Perdomo 2019, Gómez et al., en curso). Quienes permanecen en el país continúan haciendo contratos, planificando negocios, manejando las difíciles relaciones entre las empresas y los organismos estatales, y haciendo las funciones cuasinotariales como tramitar divorcios, declarar sucesiones, redactar y formalizar documentos. Naturalmente las firmas de abogados han reducido su tamaño (Gómez y Pérez Perdomo 2018).

La gran crisis económica y humanitaria de Venezuela no ha destruido, o no lo ha hecho enteramente, los mecanismos de convivencia social. Las personas hacen colas y tienden a respetar el orden de ellas, pagan sus cuentas en restaurantes y generalmente los vecinos no se roban ni se matan entre sí. Tradicionalmente las señales de tránsito se han tomado como sugerencias y se las sigue tomando de esa manera: no es perceptible que se hayan incrementado sustancialmente los choques y accidentes. En otras palabras, en contra de la hipótesis hobbesiana que la desaparición del Estado conduce a una guerra de todos contra todos, esto no se ha cumplido, aunque la vida social se ha hecho más pobre,

${ }^{30}$ Andrea Santacruz, coautora de este trabajo, es una abogada activa en materia penal con varios casos de significación política. Las afirmaciones corresponden a su experiencia personal y a conversaciones con sus colegas que también defienden perseguidos políticos. 
violenta y desagradable. Hay ciertamente signos de anomia, pero no puede decirse que la sociedad venezolana del presente sea completamente anómica (Pérez-Perdomo y Santacruz 2016).

Quienes firman un contrato en Venezuela saben que difícilmente podrán pedir la ejecución judicial. La pregunta es por qué se firma, por qué se les pide a los abogados que intervengan en su redacción. La respuesta deberá ser estudiada con profundidad, pero se puede formular la hipótesis que el derecho cumple una función de solemnización. El acuerdo podría ser puramente verbal y aun así las promesas deben ser cumplidas por imperativo moral y por el uso social, pero la formalización del contrato claramente agrega un valor: precisa las promesas y hace que las personas se sientan más obligadas. El derecho no desaparece aun cuando el Estado deje de funcionar, pero obviamente cumplirá mejor su papel si el Estado funciona como Estado de derecho.

Esta constatación final es un llamado a la esperanza. A pesar de un régimen que ha desatado una represión generalizada y ha pervertido el aparato de justicia, los venezolanos seguimos creyendo en el derecho y que, una vez recuperado el funcionamiento del Estado, éste pueda ser la garantía de la libertad.

\section{Referencias}

Acceso a la Justicia, 2018. La Sala Plena ordena el enjuiciamiento del Diputado Juan Requesens. Acceso a la Justicia [en línea], 8 de agosto. Disponible en: https://www.accesoalajusticia.org/antejuicio-de-merito-contra-el-diputado-juanrequesens/ [Con acceso el 12 de febrero de 2020].

Acceso a la Justicia, 2019. La ilegítima ANC reforzó el control social y político sobre la población. Acceso a la Justicia [en línea], 6 de septiembre. Disponible en: https://www.accesoalajusticia.org/ilegitima-anc-reforzo-control-social-politicopoblacion/ [Con acceso el 12 de febrero de 2020].

Alguindigue, C., y Pérez-Perdomo, R., 2013. Revolución y proceso penal en Venezuela 1999-2012. Anales de la Universidad Metropolitana [en línea], 13(2). Disponible en: https://dialnet.unirioja.es/servlet/articulo?codigo=4709912 [Con acceso el $12 \mathrm{de}$ febrero de 2020].

Alto Comisionado de las Naciones Unidas para los Refugiados, 2019. Situación en Venezuela [en línea]. ACNUR España. Disponible en:

https://www.acnur.org/situacion-en-venezuela.html [Con acceso el 12 de febrero de 2020].

Amnistía Internacional Venezuela, 2018a. Bassil Da Costa Frías: Conmemoración de su muerte durante participación en una manifestación el $12 f 2014$ [en línea]. Amnistía Internacional Venezuela, 25 de enero. Entrada de blog. Disponible en: https://www.amnistia.org/ve/blog/2018/01/4650/bassil-da-costa-frias-asesinadoen-una-manifestacion-el-12f-2014 [Con acceso el 12 de febrero de 2020].

Amnistía Internacional Venezuela, 2018b. David José Vallenilla: Más de un año sin justicia tras su muerte durante las protestas [en línea]. Amnistía Internacional Venezuela, 31 de agosto. Entrada de blog. Disponible en: https://www.amnistia.org/Ve/Blog/2018/08/7612/David-vallenilla-mas-de-1-ano- 
sin-justicia-tras-su-mUerte-durante-las-protestas [Con acceso el 12 de febrero de 2020].

Amnistía Internacional, 2015. Venezuela: Víctimas de violaciones de derechos humanos durante protestas, exigiendo justicia. Christian Holdack debe ser liberado [en línea]. Marzo. Disponible en: http://w2.ucab.edu.ve/tl files/CDH/Lineastematicas/Amnistia\%20Internacional\% 20Christian\%20Holdack.pdf [Con acceso el 12 de febrero de 2020].

Amnistía Internacional, 2018. Esto no es vida: Seguridad ciudadana y derecho a la vida en Venezuela (MR 53/8975/2018) [en línea]. Londres: Amnistía Internacional. Disponible en: https://www.amnesty.org/download/Documents/AMR5389752018SPANISH.PDF [Con acceso el 12 de febrero de 2020].

Amnistía Internacional, 2019. Hambre de Justicia: Crímenes de lesa humanidad en Venezuela [en línea]. Mayo. Disponible en:

https://www.amnesty.org/download/Documents/AMR5302222019SPANISH.PDF [Con acceso el 12 de febrero de 2020].

Analítica, 2019. ONG exige investigación para los involucrados en asesinato de Geraldine Moreno. Analítica [en línea], 22 de febrero. Disponible en: https://www.analitica.com/actualidad/actualidad-nacional/organizacion-justiciaencuentro-y-perdon-exige-investigacion-para-los-involucrados-en-asesinato-degeraldin-moreno/ [Con acceso el 12 de febrero de 2020].

Ávila, K., 2017. Las Operaciones de Liberación del Pueblo (OLP) entre las ausencias y los excesos del sistema penal de Venezuela. Crítica Penal y Poder [en línea], n.o 12. Disponible en:

http://revistes.ub.edu/index.php/CriticaPenalPoder/article/view/16878 [Con acceso el 12 de febrero de 2020].

Ávila, K., 2019. Uso de la fuerza pública y derecho a la vida en Venezuela. Serie Investigaciones en Derechos Humanos [en línea], n.․․ 1. Caracas. PROVEA.

Disponible en: https://www.derechos.org.ve/web/wp-content/uploads/uso-de-lafuerza-p\%C3\%BAblica.pdf [Con acceso el 12 de febrero de 2020].

Bournemouth University's Civic Media Hub y The Omega Research Foundation, 2016. Use of Tear Gas on Peaceful Protesters by Council of Europe Member States [en línea]. Informe. Civic Media Hub, 25 de febrero. Disponible en: http://www.civicmedia.io/wp-content/uploads/2016/02/USE-OF-TEAR-GAS-ONPEACEFUL-PROTESTERS-BY-COUNCIL-OF-EUROPE-MEMBERSTATES final.pdf [Con acceso el 12 de febrero de 2020].

Brewer-Carías, A., 2017a. El golpe de Estado judicial continuado, la no creíble defensa de la Constitución por parte de quien la despreció desde siempre, y el anuncio de una bizarra "revisión y corrección" de sentencias por el juez constitucional por órdenes del poder ejecutivo (Secuelas de las sentencias № 155 y 156 de 27 y 29 de marzo de 2017). Revista de Derecho Público, n. ${ }^{-}$149-150, pp. 301-312.

Brewer-Carías, A., 2017b. Opinión: Acerca de la usurpación de funciones por el Tribunal Supremo de Venezuela y la consolidación de una dictadura judicial. 
Diario Constitucional [en línea], 31 de marzo. Disponible en: https://www.diarioconstitucional.cl/noticias/actualidadinternacional/2017/03/31/opinion-acerca-de-la-usurpacion-de-funciones-por-eltribunal-supremo-de-venezuela-y-la-consolidacion-de-una-dictadura-judicial/ [Con acceso el 12 de febrero de 2020].

Briceño-León, R., Ávila, O., y Camardiel, A., eds., 2012. Violencia e institucionalidad. Informe del Observatorio Venezolano de Violencia [en línea]. Caracas: Alfa. Disponible en: http://observatoriodeviolencia.org.ve/wp-content/uploads/2019/11/PDFViolencia-e-institucionalidad.pdf [Con acceso el 12 de febrero de 2020].

Canova, A., et al., 2014. El TSJ al servicio de la revolución. Caracas: Galipán.

Capriles, V., y Pérez Perdomo, R., 2019. Los abogados graduados en la Universidad Metropolitana de Venezuela (2006-2016). Estudio de una cohorte profesional en tiempos de revolución. Revista Pedagogía Universitaria y Didáctica del Derecho [en línea], 6(1), 23-42. Disponible en: https://doi.org/10.5354/0719-5885.2019.53744 [Con acceso el 12 de febrero de 2020].

Casey, N., 2018. Jets, caballos y sobornos: cómo un funcionario venezolano se hizo multimillonario mientras su país colapsaba. New York Times [en línea], 26 de noviembre. Disponible en: https://www.nytimes.com/es/2018/11/26/venezuelasobornos-alejandro-andrade/ [Con acceso el 12 de febrero de 2020].

CDH-UNIMET [@cdhunimet], 2019. Desde el CDH-UNIMET repudiamos la muerte bajo custodia del Capitán de Corbeta Rafael Acosta Arévalo, detenido arbitrariamente el viernes 21 de junio de 2019 y trasladado siete días después, el 28 de junio, a una sede judicial para la realización de la Audiencia de Presentación, a pesar de que la Constitución establece que esto debe ocurrir dentro de las 48 horas siguientes a la detención. Instagram [en línea], 30 de junio. Disponible en: https://www.instagram.com/p/BzVuaqTjq1O/ [Con acceso el $12 \mathrm{de}$ febrero de 2020].

CDH-UNIMET [@cdhunimet], 2020. Comunicado del@CDHUNIMET frente a los hechos ocurridos el día de hoy, 5 de enero de 2020. Instagram [en línea], 5 de enero. Disponible en: https://www.instagram.com/p/B69GBkJjK05/ [Con acceso el 12 de febrero de 2020].

Civilis Derechos Humanos et al., 2019. Manual sobre el Derecho a la Protección Internacional en Crisis Mayores, 2019 [en línea]. Caracas: Civilis Derechos Humanos/CDH-UNIMET/CDH-UCAB/Acceso a la Justicia. Disponible en: http://www.civilisac.org/civilis/wp-content/uploads/Manual-Derecho-a-laProtección-Internacional-2019.doc-1-1.pdf [Con acceso el 12 de febrero de 2020].

Comisión Interamericana de Derechos Humanos, 2017. Institucionalidad democrática, Estado de derecho y derechos humanos en Venezuela (OEA/Ser.L/V/II.Doc. 209) [en línea]. Informe de País. 31 de diciembre. Disponible en: http://www.oas.org/es/cidh/informes/pdfs/Venezuela2018-es.pdf [Con acceso el 12 de febrero de 2020].

Comisión Interamericana de Derechos Humanos, 2018. Informe de país, Situación de Derechos Humanos en Venezuela (OEA/Ser.L/V/II.Doc.209/17) [en línea]. 
Disponible en: $\underline{\text { http://www.oas.org/es/cidh/informes/pdfs/Venezuela2018-es.pdf }}$ [Con acceso el 12 de febrero de 2020].

Comité Jurídico Interamericano, 1990. Principios y directrices sobre la defensa pública en las Américas (CJI/doc.509/16 rev.2) [en línea]. Informe. Washington, DC:

Organización de los Estados Americanos. Disponible en:

http://www.oas.org/es/sla/cji/docs/C]I-doc 509-16 rev2.pdf [Con acceso el $12 \mathrm{de}$ febrero de 2020].

Con El Mazo Dando, 2017. Sepa la verdadera razón de la visita de expresidentes a Venezuela. Con El Mazo Dando [en línea], 19 de julio. Entrada de blog. Disponible en: https://www.conelmazodando.com.ve/sepa-la-verdadera-razon-de-la-visitade-expresidentes-a-venezuela-terroristas/ [Con acceso el 12 de febrero de 2020].

Corte Penal Internacional, 2018. Informe sobre las actividades de examen preliminar 2018 [en línea]. La Haya: Corte Penal Internacional. 5 de diciembre. Disponible en: https://www.icc-cpi.int/itemsDocuments/2018-otp-rep-PE-Venezuela.pdf [Con acceso el 12 de febrero de 2020].

Deniz, R., 2019. ¿Necesita lavar su reputación? Se alquilan diputados para tal fin. Armando info [en línea], 1 de diciembre. Disponible en: https://armando.info/Reportajes/Details/2614 [Con acceso el 12 de febrero de 2020].

EFE, 2018. Alto comisionado de la ONU cuestionó legitimidad de elecciones en Venezuela. El Nacional [en línea], 7 de marzo. Disponible en: http://www.elnacional.com/noticias/mundo/alto-comisionado-onu-cuestiono-legitimidadelecciones-venezuela 225856 [Con acceso el 12 de febrero de 2020].

EFE, 2019. Imputan a dos policías en caso de concejal venezolano fallecido en prisión. El Nuevo Herald [en línea], 2 de septiembre. Disponible en:

https://www.elnuevoherald.com/noticias/mundo/america-latina/venezuelaes/article234643707.html [Con acceso el 12 de febrero de 2020].

El Nacional, 2019. MP acusó a los dos politáchira que dejaron ciego a Rufo Chacón. El Nacional [en línea], 21 de agosto. Disponible en:

https://www.elnacional.com/venezuela/mp-acuso-a-los-dos-politachira-quedejaron-ciego-a-rufo-chacon/ [Con acceso el 12 de febrero de 2020].

El País, 2018. Lo que sabemos (y no sabemos) del atentado contra Maduro. El País [en línea], 6 de agosto. Disponible en:

https://elpais.com/internacional/2018/08/05/actualidad/1533490150 020621.html [Con acceso el 12 de febrero de 2020].

Estatuto de Roma de la Corte Penal Internacional, 1998 [en línea]. Aprobado en Roma, Italia, el 17 de julio de 1998 por la Conferencia Diplomática de Plenipotenciarios de las Naciones Unidas sobre el establecimiento de una Corte Penal Internacional. Asamblea General de Naciones Unidas. Disponible en: https://www.refworld.org.es/docid/50acc1a12.html [Con acceso el 12 de febrero de 2020].

Foro Penal, 2019. La represión en Venezuela en cifras: Datos del foro penal al 19 de agosto de 2019 [en línea]. Foro Penal. Disponible en: https://foropenal.com/wp- 
content/uploads/2019/08/cifras-de-represion-al-19082019-definitiva.pdf [Con acceso el 12 de febrero de 2020].

Fréitez Landaeta, A., coord., 2018. Encuesta Nacional de Condiciones de Vida (ENCOVI). Avances de Resultados. El Ucabista [en línea]. UCAB / Universidad Central / USB. Noviembre. Disponible en: https://elucabista.com/wpcontent/uploads/2018/11/RESULTADOS-PRELIMINARES-ENCOVI-2018-30nov.pdf [Con acceso el 12 de febrero de 2020].

García Marco, D., 2016. “Una pena de muerte disimulada”: la polémica Operación de Liberación del Pueblo, la mano dura del gobierno de Venezuela contra el crimen. $B B C$ Mundo Caracas [en línea], 28 de noviembre. Disponible en: https://www.bbc.com/mundo/noticias-america-latina-38126651 [Con acceso el 12 de febrero de 2020].

Gómez, M., 2015. La manipulación del derecho a través de la agenda social: el caso de las misiones bolivarianas. Caracas: Universidad Metropolitana/Academia de Ciencias Políticas y Sociales.

Gómez, M., y Pérez-Perdomo, R., eds., 2018. Big Law in Latin America and Spain: Globalization and Adjustments in the Provision of High-End Legal Services. Nueva York: Palgrave Macmillan.

Guillén, A., 2018. A un año del asesinato de su hijo, David Vallenilla lucha contra la impunidad. Proiuris [en línea], 21 de junio. Disponible en: http://proiuris.org/?p=49441 [Con acceso el 12 de febrero de 2020].

Hernández, O., 2014. ¿Por qué reemplazaron al ministro de Interior de Venezuela, Miguel Rodríguez Torres? CNN Español [en línea], 27 de octubre. Disponible en: https://cnnespanol.cnn.com/2014/10/27/por-que-reemplazaron-al-ministro-deinterior-de-venezuela-miguel-rodriguez-torres/ [Con acceso el 12 de febrero de 2020].

Instituto Nacional de Estadística, 2019. Población Proyectada al 30/06/2019 - Base Censo 2011. Caracas: INE.

José Vicente Hoy [Jose Vicente HOY], 2018. Entrevista a Delcy Rodríguez y los confidenciales. YouTube [en línea], 24 de junio. Disponible en: https://www.youtube.com/watch?v=K4a0jxr-ruc [Con acceso el 12 de febrero de 2020].

Justicia, Encuentro y Perdón, 2019. Geraldín Moreno: símbolo de la vida en resistencia frente al abuso de autoridad. JEP Venezuela [en línea], 22 de junio. Disponible en: https://www.jepvenezuela.com/cronica-geraldin-moreno-simbolo-de-la-vida-enresistencia-frente-al-abuso-de-autoridad/ [Con acceso el 12 de febrero de 2020].

Kurmanaev, A., 2019. Venezuela's Collapse Is the Worst Outside of War in Decades, Economists Say. The New York Times [en línea], 17 de mayo. Disponible en: https://www.nytimes.com/2019/05/17/world/americas/venezuela-economy.html [Con acceso el 12 de febrero de 2020].

López Maya, M., 2016. El ocaso del chavismo 2005-2015. Caracas: Alfa. 
Lostal Becceril, M., Hunter, E., y Utmelidze, I., 2017. Crímenes de Lesa Humanidad: Investigación y Determinación de los Hechos, Análisis del Caso [en línea]. Centre for International Law Research and Policy, Case Matrix Network. Febrero. Disponible en: https://www.legal-tools.org/doc/66bb47/pdf/ [Con acceso el $12 \mathrm{de}$ febrero de 2020].

Melgar, A., 2019a. Cuerpo de Acosta fue reconocido y será enterrado en una inhumación controlada. CNN Español [en línea], 10 de julio. Disponible en: https://cnnespanol.cnn.com/2019/07/10/cuerpo-de-acosta-fue-reconocido-y-seraenterrado-en-una-inhumacion-controlada/ [Con acceso el 12 de febrero de 2020].

Melgar, A., 2019b. Joven venezolano pierde la vista tras ser herido por policías. CNN Español [en línea], 2 de julio. Disponible en:

https://cnnespanol.cnn.com/2019/07/02/alerta-joven-venezolano-pierde-la-vistatras-ser-herido-por-policias/ [Con acceso el 12 de febrero de 2020].

Meza, A., 2014. Venezuela alcanza la inflación más alta del mundo. El País [en línea], 12 de febrero. Disponible en:

https:/elpais.com/economia/2014/02/12/actualidad/1392224609 187490.html [Con acceso el 12 de febrero de 2020].

Morales, A., 2019. Tribunal niega justicia en caso Fabián Urbina a dos años de su asesinato. El Pitazo [en línea], 19 de junio. Disponible en:

https://elpitazo.net/centro/tribunal-niega-justicia-en-caso-fabian-urbina-a-dosanos-de-su-asesinato/ [Con acceso el 12 de febrero de 2020].

Moreno, V., 2017. "Wilmito" fue asesinado a tiros dentro de la cárcel de Tocorón. Efecto Cocuyo [en línea], 1 de abril. Disponible en:

https://efectococuyo.com/sucesos/wilmito-fue-asesinado-a-tiros-dentro-de-lacarcel-de-tocoron/ [Con acceso el 12 de febrero de 2020].

Naciones Unidas, 2014. Informe del Relator Especial sobre las ejecuciones extrajudiciales, sumarias o arbitrarias, Christof Heyns (Doc. A/HRC/26/36) [en línea]. Nueva York: Asamblea General de Naciones Unidas, 1 de abril. Disponible en: https://www.acnur.org/fileadmin/Documentos/BDL/2014/9615.pdf [Con acceso el 12 de febrero de 2020].

Naciones Unidas, 2017. Muerte ilícita de refugiados y migrantes: Informe de la Relatora Especial del Consejo de Derechos Humanos sobre las ejecuciones extrajudiciales, sumarias $y$ arbitrarias (A/72/335) [en línea]. Nueva York: Asamblea General de Naciones Unidas, 15 de agosto. Disponible en: https://undocs.org/es/A/72/335 [Con acceso el 12 de febrero de 2020].

Neuman, W., 2015. Venezuelan Prosecutor Ties Nicolás Maduro to Arrests. New York Times [en línea], 28 de octubre. Disponible en: https://www.nytimes.com/2015/10/29/world/americas/venezuelan-prosecutorties-nicolas-maduro-to-arrests.html?smtyp=cury $\mathrm{r}=0$ [Con acceso el 12 de febrero de 2020].

Observatorio Venezolano de Conflictividad Social, 2014. Conflictividad social en Venezuela en 2014 [en línea]. Caracas: OVCS. Disponible en: http://observatoriodeconflictos.org.ve/oc/wp- 
content/uploads/2015/01/Conflictividad-en-Venezuela-2014.pdf [Con acceso el 12 de febrero de 2020].

Observatorio Venezolano de Conflictividad Social, 2015. Conflictividad social en Venezuela en 2015. Caracas: OVCS.

Observatorio Venezolano de Conflictividad Social, 2017. Conflictividad social en Venezuela en 2017 [en línea]. Caracas: OVCS. Disponible en:

https://www.observatoriodeconflictos.org.ve/oc/wpcontent/uploads/2018/01/Conflictividad-social-en-Venezuela-2017-1.pdf [Con acceso el 12 de febrero de 2020].

Observatorio Venezolano de Conflictividad Social, 2019. Durante el primer semestre de 2019 se documentaron 10.477 protestas [en línea]. Caracas: OVCS. Disponible en: https://www.observatoriodeconflictos.org.ve/tendencias-de-la-conflictividad/10477-protestas-registradas-en-el-primer-semestre [Con acceso el 12 de febrero de 2020].

Observatorio Venezolano de Violencia, 2018. OVV-LACSO: Informe Anual de Violencia 2018 [en línea]. Caracas: OVV. 31 de diciembre. Disponible en https://observatoriodeviolencia.org.ve/ovv-lacso-informe-anual-de-violencia2018/

Oficina del Alto Comisionado de las Naciones Unidas para los Derechos Humanos, 2018. Violaciones de los derechos humanos en la República Bolivariana de Venezuela: una espiral descendente que no parece tener fin [en línea]. Ginebra: ACNUDH. Junio. Disponible en: https://www.ohchr.org/Documents/Countries/VE/VenezuelaReport2018 SP.pdf [Con acceso el 12 de febrero de 2020].

Oficina del Alto Comisionado de las Naciones Unidas para los Derechos Humanos, 2019. Informe de la Oficina de las Naciones Unidas para los Derechos Humanos sobre Venezuela insta a adoptar de inmediato medidas para detener y remediar graves violaciones de derechos [en línea]. Ginebra: ACNUDH. 4 de julio. Disponible en: https://www.ohchr.org/SP/NewsEvents/Pages/DisplayNews.aspx?NewsID=24788 \&LangID=S [Con acceso el 12 de febrero de 2020].

Olmo, G., 2018. Muerte de Fernando Albán en una comisaría del Sebin: 3 incógnitas del caso del opositor que falleció en Venezuela. BBC Mundo [en línea], 10 de octubre. Disponible en: https://www.bbc.com/mundo/noticias-america-latina-45817059 [Con acceso el 12 de febrero de 2020].

Olmo, G., 2020. Luis Parra y Juan Guaidó: qué puede pasar en Venezuela tras la polémica proclamación de dos presidentes de la Asamblea Nacional. BBC Mundo [en línea], 6 de enero. Disponible en: https://www.bbc.com/mundo/noticiasamerica-latina-51003684 [Con acceso el 12 de febrero de 2020].

Organización de los Estados Americanos, 2017. Venezuela: Secretario General de la OEA denuncia Autogolpe de Estado (E-019/17) [en línea]. Comunicado de prensa. OEA, 30 de marzo. Disponible en:

https://www.oas.org/es/centro noticias/comunicado prensa.asp?sCodigo=C019/17 [Con acceso el 12 de febrero de 2020]. 
Organización de los Estados Americanos, 2018. Informe de la Secretaría General de la Organización de los Estados Americanos y del panel de expertos internacionales independientes sobre la posible comisión de crímenes de lesa humanidad en Venezuela [en línea]. Washington, DC: OEA, 29 de mayo. Disponible en: http://www.oas.org/documents/spa/press/Informe-Panel-IndependienteVenezuela-ES.pdf [Con acceso el 12 de febrero de 2020].

Ortega, L., 2012. Violencia e impunidad de los grupos policiales en Venezuela. En: R. Briceño-León, O. Ávila y A. Camardiel, eds., Violencia e institucionalidad. Informe del Observatorio Venezolano de Violencia [en línea]. Caracas: Alfa, 289-298.

Disponible en: http://observatoriodeviolencia.org.ve/wpcontent/uploads/2019/11/PDF-Violencia-e-institucionalidad.pdf [Con acceso el 12 de febrero de 2020].

Osorio, J., sin fecha. Ver la muerte a los ojos y resistir. Crónicas insumisas [en línea]. Instituto Prensa y Sociedad. Disponible en: https://ipysvenezuela.org/cronicasinsumisas/?page $\mathrm{id}=680$ [Con acceso el 12 de febrero de 2020].

Pérez de Armiño, K., y Areizaga, M., 2000. Emergencia Compleja. En: K. Pérez de Armiño, dir., Icaria y Hegoa, eds., Diccionario de Acción Humanitaria y Cooperación al Desarrollo [en línea]. Universidad del País Vasco. Disponible en: http://www.dicc.hegoa.ehu.es/listar/mostrar/85 [Con acceso el 12 de febrero de 2020].

Pérez-Perdomo, R., 2014. Represión y justicia en tiempos de protesta. Debates/Revista de Ciencias Políticas, 8(3).

Pérez-Perdomo, R., 2015. Las revistas jurídicas venezolanas en tiempos de revolución. Boletín Mexicano de Derecho Comparado [en línea], 48(42). Disponible en: https://doi.org/10.22201/iij.24484873e.2015.142.4920 [Con acceso el 12 de febrero de 2020].

Pérez-Perdomo, R., y Santacruz, A., 2016. La legitimidad de los jueces y legisladores en el estado constitucional de derecho: La Asamblea Nacional y el Tribunal Supremo venezolano en 2016. Doxa Cuadernos de Filosofía del Derecho [en línea], n. 39. Disponible en: https://doi.org/10.14198/DOXA2016.39.22 [Con acceso el 12 de febrero de 2020].

Pérez-Perdomo, R., y Santacruz, A., 2017. The Chavist revolution and the justice system. Latin American Policy [en línea], 8(2). Disponible en: https://doi.org/10.1111/lamp.12126 [Con acceso el 12 de febrero de 2020].

Plazas, N., 2019. Gobierno venezolano sostiene haber neutralizado un "intento de golpe de Estado". France24 [en línea], 27 de junio. Disponible en: https://www.france24.com/es/20190627-venezuela-gobierno-maduro-golpeestado [Con acceso el 12 de febrero de 2020].

Prensa Unidad Venezuela, 2017. El pueblo decidió: 7.186.170 venezolanos expresaron su rechazo a la constituyente. Unidad Venezuela [en línea], 16 de julio. Disponible en: http://www.unidadvenezuela.org/noticias/7566=el-pueblo-decidio-7186170venezolanos-expresaron-su-rechazo-a-la-constituyente [Con acceso el 12 de febrero de 2020]. 
Prieto, D., 2019. Juez Padilla admitió todos los cargos imputados a Juan Requesens por el MP. El Universal [en línea], 1 de julio. Disponible en:

https://www.eluniversal.com/politica/44402/requesens-fue-acusado-de-

homicidio-intencional-calificado-con-alevosia-frustrado [Con acceso el $12 \mathrm{de}$ febrero de 2020].

PROVEA, 2019a. Condena de implicados en asesinato de Rafael Acosta es insuficiente y alienta uso de la tortura [en línea]. PROVEA, 25 de septiembre. Disponible en:

https://www.derechos.org.ve/actualidad/condena-de-implicados-en-asesinato-derafael-acosta-es-insuficiente [Con acceso el 12 de febrero de 2020].

PROVEA, 2019b. El andamiaje jurídico con el que se promueve y consolida el paramilitarismo en Venezuela. Un sistema para ejercer violencia contra el pueblo [en línea]. PROVEA, 18 de abril. Disponible en: https://www.derechos.org.ve/informes-especiales/elandamiaje-juridico-con-el-que-se-promueve-y-consolida-el-paramilitarismo-envenezuela-un-sistema-para-ejercer-violencia-contra-el-pueblo [Con acceso el 12 de febrero de 2020].

Redacción BBC Mundo, 2016. Venezuela: el CNE paraliza el referendo revocatorio a Nicolás Maduro. BBC News Mundo [en línea], 21 de octubre. Disponible en: https://www.bbc.com/mundo/noticias-america-latina-37723172 [Con acceso el 12 de febrero de 2020].

Redacción BBC Mundo, 2017. El Tribunal Supremo y la fiscal Luisa Ortega Díaz se enfrentan en medio del clima de tensión política en Venezuela. BBC News Mundo [en línea], 21 de junio. Disponible en: https://www.bbc.com/mundo/noticiasamerica-latina-40350598 [Con acceso el 12 de febrero de 2020].

Redacción Web Panorama, 2020. Chavismo, sin quórum, juramentó a Luis Parra como "presidente" de la AN. Panorama [en línea], 5 de enero. Disponible en: https://www.panorama.com.ve/politicayeconomia/URGENTE-Chavismo-sinquorum-juramento-a-Luis-Parra-como-presidente-de-la-AN-20200105-0026.html [Con acceso el 12 de febrero de 2020].

Reverol, N. [@NestorReverol], 2018. 1. Se tuvo conocimiento del suicidio de Fernando Alban, quien se encontraba detenido en el Sebin desde el 5 Octubre por la investigación del magnicidio frustrado y estar involucrado en actos desestabilizadores dirigidos desde el exterior, de los cuales, existen suficientes pruebas. Twitter [en línea], 8 de octubre. [Cuenta suspendida y tuit eliminado].

Rodelo, L., 2019. Juancho Montoya: un líder de colectivos asesinado por su mano derecha el \#12Feb de 2014. El Pitazo [en línea], 12 de febrero. Disponible en: https:/elpitazo.net/gran-caracas/juancho-montoya-un-lider-de-colectivosasesinado-por-su-mano-derecha-el-12-de-febrero-de-2014/ [Con acceso el $12 \mathrm{de}$ febrero de 2020].

Rodríguez, R., 2019. Fiscalía acusa a dos funcionarios del Sebin por caso de concejal Albán. Efecto Cocuyo [en línea], 2 de septiembre. Disponible en: https://efectococuyo.com/sucesos/fiscalia-acusa-a-dos-funcionarios-del-sebin-porcaso-de-concejal-alban/ [Con acceso el 12 de febrero de 2020]. 
S.I., 2016. Franklin Nieves, el fiscal que surgió de la nada. $A B C$ [en línea], 8 de julio. Disponible en: https://www.abc.es/internacional/abci-franklin-nieves-fiscalsurgio-nada-201607081143 noticia.html [Con acceso el 12 de febrero de 2020].

Santos, B. de S., 2013. Chávez: el legado y los desafíos. Aporrea [en línea], 9 de marzo. Disponible en:www.aporrea.org/actualidad/a160870.html [Con acceso el 12 de febrero de 2020].

Santos, B. de S., 2017. En defensa de Venezuela. Question Digital [en línea], 26 de julio. Disponible en: http://questiondigital.com/boaventura-de-sousa-santos-endefensa-de-venezuela/ [Con acceso el 12 de febrero de 2020].

Smith, S., y Armario, C., 2018. Venezuelan government: Drone strikes targeted Maduro. The Associated Press [en línea], 4 de agosto. Disponible en: https://www.apnews.com/ba6e6ef53ea34030b1e1b4c5fca79a6d [Con acceso el 12 de febrero de 2020].

Staff de PanAm Post, 2015. Nicolás Maduro lanza “Estado Mayor de Guerra Económica". PanAm Post [en línea], 1 de enero. Disponible en: https:/es.panampost.com/panam-staff/2014/12/24/nicolas-maduro-lanza-estadomayor-de-guerra-economica/ [Con acceso el 12 de febrero de 2020].

TalCual, 2020. Regresan a sede de PoliTáchira a funcionarios acusados de agredir a Rufo Chacón. TalCual [en línea], 28 de enero. Disponible en: https://talcualdigital.com/regresan-a-sede-de-politachira-a-funcionariosacusados-de-agredir-a-rufo-chacon/ [Con acceso el 12 de febrero de 2020].

TeleSur TV, 2017. Maduro activa primera fase del Plan Zamora para la seguridad del país. YouTube [en línea], 18 de abril. Archivo de vídeo. Disponible en: https://www.youtube.com/watch?v=Gk3DE0GwYaAyt=16s [Con acceso el $12 \mathrm{de}$ febrero de 2020].

TRIAL International, 2019. Arbitrary Detention [en línea] Ginebra: TRIAL International. Disponible en: https://trialinternational.org/topics-post/arbitrary-detention/ [Con acceso el 12 de febrero de 2020].

Vallenilla, D. [@dvallenilla8], 2018. Exijo Justicia para mi Hijo. \#davidvallenilla. Instagram [en línea], 21 de septiembre. Vídeo. Disponible en: https://www.instagram.com/p/Bn98sPtA61i/ [Con acceso el 12 de febrero de 2020].

Versión Final, 2017. Andrés Eloy Méndez: Fiscal tiene agenda para levantar más violencia. Versión Final [en línea], 1 de junio. Disponible en: http://versionfinal.com.ve/politica-dinero/andres-eloy-mendez-fiscal-tieneagenda-para-levantar-mas-violencia/ [Con acceso el 12 de febrero de 2020].

Vivanco, J., y Taraciuk, T., 2018. Autoridades venezolanas deben ser castigadas por sus crímenes. Human Rights Watch [en línea], 23 de enero. Publicado en El Mercurio. Disponible en: https://www.hrw.org/es/news/2018/01/23/autoridadesvenezolanas-deben-ser-castigadas-por-sus-crimenes [Con acceso el 12 de febrero de 2020]. 
Vivanco, J.M., 2017. Se desmorona la fachada democrática venezolana. Human Rights Watch News [en línea], 31 de marzo. Publicado originalmente en Univisión. Disponible en: https://www.hrw.org/es/news/2017/03/31/se-desmorona-lafachada-democratica-venezolana [Con acceso el 12 de febrero de 2020].

Von Bergen, F., 2014. Los colectivos y el poder [Reportaje de investigación]. Siete Días, 23 de abril, pp. 1-3.

\section{Sentencias}

Corte Interamericana de Derechos Humanos. Diego García-Sayán. Caso Díaz Peña v Venezuela. Sentencia de 26 de junio de 2012 [en línea]. Disponible en:

http://www.corteidh.or.cr/docs/casos/articulos/seriec 244 esp.pdf [Con acceso el 12 de febrero de 2020].

Corte Interamericana de Derechos Humanos. Presidente: Héctor Fix-Zamudio. Caso El Amparo v Venezuela. Sentencia de 14 de septiembre de 1996 [en línea]. Disponible en: http://www.corteidh.or.cr/docs/casos/articulos/seriec 28 esp.pdf [Con acceso el 12 de febrero de 2020].

Tribunal Supremo de Justicia en Sala Plena. Sentencia n 48 del 08-08-2018.

Tribunal Supremo de Justicia, Sala Constitucional. Sentencia n.․ำ 155 del 28 de marzo de 2017.

Tribunal Supremo de Justicia, Sala Constitucional. Sentencia n. ${ }^{\circ} 156$ del 29 de marzo de 2017.

Tribunal Supremo de Justicia, Sala Constitucional. Sentencia n. .276 del 24 de abril de 2014.

Tribunal Supremo de Justicia, Sala Constitucional. Sentencia n. 526. 